\title{
Assessing the Trends of Energy Use of Public Non-Domestic Buildings in England and Wales
}

\author{
Hong, S. ${ }^{1}$, Mylona, A. ${ }^{2}$, Davies, H. $^{2}$, Ruyssevelt, P. ${ }^{3}$, Mumovic, D. ${ }^{1}$ \\ ${ }^{1}$ UCL Institute for Environmental Design \& Engineering, London, United Kingdom \\ 2 The Chartered Institution of Building Services Engineers, Balham, United Kingdom \\ ${ }^{3}$ UCL Energy Institute, London, United Kingdom
}

\begin{abstract}
Accessing sufficient data for understanding how energy is used in non-domestic buildings is deemed to be a challenge in many countries. In the UK, such a challenge has led to limited understanding of long term changes in energy use of buildings. This study aims to develop a deeper understanding of the trends in energy use across the public sector non-domestic buildings in England. Display Energy Certificate (DEC) data which relate to 59,740 public sector non-domestic buildings in England and Wales was analysed. Statistical analyses were carried out to understand both the latest patterns of energy use and how they have changed between 2010 and 2016. The patterns of energy use of various public-sector buildings were found to have gradually changed over the seven-year period. An imminent release of a revised dataset was deemed necessary for understanding the performance of buildings to support the aspirations set out in the Clean Growth Strategy. The study pointed to a need for regularly gathering and sharing data for understanding the changes in the patterns of energy use of the stock. Developing a framework that can facilitate this would enable various stakeholders make informed decisions for improving energy efficiency of the UK's non-domestic buildings.
\end{abstract}

Practical application: Statistics on electrical and fossil-thermal energy use intensity provide up-to-date reference points for assessing operational energy efficiency of public sector buildings. Principles for developing a framework to support various stakeholders make informed decisions on for example setting design targets or making capital investments are presented.

\section{Keywords}

Energy use, non-domestic building, long-term trend, energy benchmark 


\section{Introduction}

Understanding variations in characteristics of buildings and their long-term patterns of energy use plays an important role for encouraging improvements in operational energy efficiency of buildings. Despite the importance, obtaining sufficient and appropriate empirical data has been considered to be a challenge in many countries, including the UK (1-3). For buildings to contribute towards achieving the UK's 2050 carbon reduction target (4), monitoring and developing a deeper understanding of such changes would be invaluable. This study therefore aims to provide insights on the implications of such a change and how the energy performance of these buildings has changed over the past seven years.

\section{Frameworks for Collecting Operational Energy Performance Data}

There are numerous frameworks that have been developed in various countries for collecting and analysing metered energy consumption data for improving the understanding of the energy performance of buildings.

Since 1979, the US Energy Information Administration (EIA), for example, have continued to systematically collect data through the Commercial Building Energy Consumption Survey (CBECS) ${ }^{1}$. By carrying out a phone survey of a large number of non-domestic buildings across the country, the EIA was able to create a database comprising detailed information about the building stock. What is more, public release of such data provided an opportunity for academics and the federal government to develop knowledge for helping buildings improve their operational energy efficiency (5-7). In the UK, Building Energy Efficiency Survey (BEES), similar to the CBECS, was carried out in 2014. Using a phone survey method, the Department of Energy and Climate Change, now part of the Department for Business, Energy \& Industrial Strategy (BEIS), was able to collect information on more than 3600 premises. Based on the survey data, BEIS published a report providing insights into how energy was being used in non-domestic premises. Unlike the CBECS however BEES was a one-off project with no specific plans being set for the near future. This meant that opportunities for understanding long-term energy performance trends, as it was done in the US, would not materialise in the UK (1).

The US Department of Energy (DoE) on the other hand has taken a different approach in recent years for collecting and sharing metered energy performance data. Rather than actively collecting a sample that is representative of the population through surveys, the department has established a framework to develop the Building Performance Database ${ }^{2}$ (BPD) that shares aggregated data from databases located across both public and private sectors. Such an approach means that a large sample of buildings with similar characteristics could be collected. According to DoE, this provides opportunities to develop a deeper understanding of how energy performance compares to peers by controlling various characteristics, which is different from perspectives that can be acquired from the CBECS data (8). As it stands however the analytical scope provided through BDP platform is limited to a 'snapshot' in time which limits possibilities of observing how the pattern changes over time.

\footnotetext{
${ }^{1}$ For CBECS, see https://www.eia.gov/consumption/commercial/

${ }^{2}$ For the Building Performance Database, see https://energy.gov/eere/buildings/about-buildingperformance-database
} 
Energy certification is another approach that has been implemented in many countries and introduces possibilities of collecting metered energy consumption data of a large number of buildings. Due to difficulties associated with cost and technical difficulty of developing databases to store the data however, only a few countries have fully harnessed the benefits of these schemes (9). Some of the successful examples include the EnergyStar ${ }^{3}$ programme in the US and the NABERS ${ }^{4}$ scheme in Australia. By providing incentives for collecting and reporting metered energy consumption data which allow the assessment of the operational energy efficiency of a large number of non-domestic buildings, these schemes were able to develop databases of unforeseen scale. In the UK, Display Energy Certificates (DECs) have been accumulated in a central database since the implementation of the Energy

Performance of Buildings Directive in the UK in 2008. The key requirement for the certificates to be lodged on an annual basis meant that empirical data on energy performance of numerous public sector non-domestic buildings were collected regularly since 2008. Despite the vast potential however, lack of interest in fully exploring the data to track progress and underpin policy making for improving energy efficiency of non-domestic buildings has been highlighted as an area the UK could improve in the future (3). This was also noted in the CIBSE and Climate Change Committee responses to a public consultation on the future of DECs in March 2015.

\section{Patterns of Energy Use of Public Sector Buildings in the UK}

Over the past decade, various studies have analysed the patterns of energy use of public sector non-domestic buildings in the UK despite the challenges of collecting sufficient data.

Armitage (10) analysed the energy performance of approximately 2600 public sector offices in the UK by using DECs from 2008 and 2009 period. While providing a useful overview of the state of energy use of offices, the study stopped short of analysing long-term trends. Brown (11) on the other hand analysed daily and weekly energy data from 300 non-domestic buildings in Leicester. A longitudinal analysis showed that between 2008 and 2011 heating consumption was reduced by $22 \%$. Increase in night-time electricity base loads were also observed over the same period. Due to the small sample size and geographical coverage however, the results were limited to the city. Similarly, Godoy-Shimizu (12) analysed the energy performance of schools using DECs lodged between 2008 and 2009. By combining data from other sources such as those by Building Research Establishment (BRE) and Department for Education, the study found that average electrical energy use intensity of primary and secondary schools have gradually increased between 1995 and 2008 whilst heating consumption was found to decrease over the same period. The analysis was however based on data from various sources without a consistent method for collecting, controlling the quality, and normalising the energy performance figures for factors such as seasonal and regional variation in weather. This limitation was overcome by a study which analysed a four-year trend of energy consumption of schools based on DECs lodged between 2008 and 2012 (13). The study found similar trends to the previous study suggesting that the trend is likely to have continued for the following years. Moreover, it was suggested that an analysis of records from DECs for a longer period would help understand whether the trend persists in the future.

Similar trend was observed from two studies that focussed on energy performance of 2000 public sector buildings in Northern Ireland $(14,15)$. The study found that electrical energy use

\footnotetext{
${ }^{3}$ For US EnergyStar, see https://www.energystar.gov/

${ }^{4}$ For NABERS, see https://nabers.gov.au/public/webpages/home.aspx
} 
in these buildings was more intensive and fossil-thermal energy use was less intensive than the benchmarks set back in 1999. These results indicated that the trend of growing electrical consumption and decreasing fossil-thermal energy use was likely to be a broader phenomenon that is not limited to England and Wales.

The review of previous studies show that there is a considerable gap in knowledge of the energy performance of buildings both in terms of activity type and trends over the past years. The evidence that exist on energy performance trends for a broad range of activity types in the non-domestic building stock, especially for those in the commercial sector, appears to be either out-dated or scarce. Small number of studies that analysed long term trends on the other hand involved a period of up to four years at the most, which may not be sufficient for detecting changes that occur during longer periods. This study therefore aims to provide insights on the latest patterns of energy use for a wide range of non-domestic buildings and how they have changed over the past seven years.

\section{Methods}

In this study, the latest set of Display Energy Certificate (DEC) data by the government has been analysed in order to understand the latest patterns of energy use of public nondomestic buildings in the UK. The data was acquired from Open Data Communities ${ }^{5}$ where the UK's Ministry of Housing, Communities and Local Government, previously Department for Communities and Local Government (DCLG), published all DEC records lodged between 9 March 2010 and 1 October 2016. This dataset comprised 215,237 records that relate to 59,740 buildings (or sites) in its raw state.

Following sections describe the process through which the raw data was prepared and analysed.

\section{Data Preparation}

In contrast to previous analyses of DECs, the raw data published by DCLG provided a restricted set of variables that were previously used for cleaning and filtering the raw data (16). There were however records that were excluded from the public release including DECs that were either cancelled or lodged voluntarily (17). There is also evidence of additional validation processes being used for improving the robustness of the data. Despite this, additional efforts were made to clean and filter the data of uncertain nature prior to analyses.

Data was cleaned and filtered over two phases based on a previously developed method (13). Through the first phase both numeric and character variables were assessed to understand the distribution of inputs and identify any outliers or uncertain values. This included assessing numeric variables such as 'ANNUAL_ELECTRICAL_FUEL_USAGE' and character variables such as 'BUILDING_ENVIRONMENT' which are directly relevant to the analyses. Through this phase, unusual input values such as negative operational ratings or missing values were flagged up for exclusion. Below is the criteria used to select records deemed to be valid:

- operational rating is not 200 or 9999

\footnotetext{
${ }^{5}$ https://epc.opendatacommunities.org/
} 
- operational rating is greater than 5 and less than 1000

- total useful floor area is greater than $50 \mathrm{~m}^{2}$

- electrical energy use intensity (EUI) is not $0 \mathrm{kWh} / \mathrm{m}^{2}$

- building is not electrically heated

- fossil-thermal EUI is not $0 \mathrm{kWh} / \mathrm{m}^{2}$

- DEC is not based on a composite methodology

The second phase involved filtering records that appears:

- to have been renewed early since after the previous certificate (in less than 6 months)

- to be duplicates based on BUILDING_REFERENCE_NUMBER, TOTAL_FLOOR_AREA, ANNUAL_ELECTRICAL_FUEL_USAGE and ANNUAL_THERMAL_FUEL_USAGE variables

- to be pro-rated certificates based on site-level energy use figures

Table 1 below shows how the number of records have changed through the cleaning and filtering process according to the criteria described above.

Table 1 Changes in the number of records before and after the cleaning process

\begin{tabular}{lcc}
\hline \multicolumn{1}{c}{ Steps } & No. records remaining after each & No. buildings (or sites) \\
\hline Raw data & 215,237 & 59,740 \\
Cleaned & 154,848 & 49,598 \\
Filtered & 37,246 & 37,246 \\
\hline
\end{tabular}

Selection of DECs for Cross-sectional and Longitudinal Analyses

The key focus of this study was to understand the latest patterns of energy use of public sector buildings in the UK as well as how they have changed over the past seven years. To do so, two samples, one for each type of analysis, were created using different methods.

\section{Cross-sectional Dataset}

A sample for analysing the latest patterns of energy use was created to assess the distribution of electrical and fossil-thermal EUI and to compare the latest performance figures against existing energy benchmarks.

DECs deemed to report the most recent energy performance of buildings were selected based on the variable 'Inspection Date'. In the absence of a variable that describes when the one-year monitoring period ended, the date when the assessor inspected a building to gather necessary information was deemed a more accurate way to approximate the date at which the one-year monitoring period ended rather than using the variable 'Lodgement Date' (16). DECs which were lodged based on information from inspections that took place throughout 2015 were selected for assessing the latest patterns of energy use. 
Benchmark categories with more than 200 buildings (or sites) were deemed to provide a more accurate representation of the patterns of energy used by buildings in each category (2). The aggregated nature of the classification system in CIBSE TM46 which groups 237 building types into 29 benchmark categories also meant that it was necessary to exclude buildings under some categories. This is due to the fact that some categories include activities (or building types) that are likely to have considerably different demand for energy (e.g. crematorium under the 'Workshop' category) and therefore likely to influence the distribution of results.

Table 2 below shows the number of records in the sample grouped by benchmark category.

Table 2 Number of buildings (or sites) included in the cross-sectional analysis. Benchmark categories highlighted in bold are benchmark categories included in the analysis.

\begin{tabular}{|c|c|c|}
\hline Main Benchmark Category & $\mathbf{N}$ & $\%$ of All \\
\hline General Office & 1885 & 11.0 \\
\hline High Street Agency & 27 & 0.2 \\
\hline General Retail & 24 & 0.1 \\
\hline Small Food Store & 1 & 0.0 \\
\hline Large Food Store & 1 & 0.0 \\
\hline Restaurant & 39 & 0.2 \\
\hline Bar, Pub Or Licensed Club & 11 & 0.1 \\
\hline Hotel & 11 & 0.1 \\
\hline Cultural Activities & 522 & 3.1 \\
\hline Entertainment Halls & 130 & 0.8 \\
\hline Swimming Pool Centre & 126 & 0.7 \\
\hline Fitness And Health Centre & 43 & 0.3 \\
\hline Dry Sports And Leisure Facility & 480 & 2.8 \\
\hline Laboratory Or Operating Theatre & 80 & 0.5 \\
\hline Public Buildings With Light Usage & 9 & 0.1 \\
\hline Schools And Seasonal Public Buildings & 9864 & 57.7 \\
\hline University Campus & 1166 & 6.8 \\
\hline Clinic & 825 & 4.8 \\
\hline Hospital - Clinical And Research & 363 & 2.1 \\
\hline Long Term Residential & 652 & 3.8 \\
\hline General Accommodation & 301 & 1.8 \\
\hline Emergency Services & 442 & 2.6 \\
\hline Public waiting or circulation & 1 & 0.0 \\
\hline Terminal & 2 & 0.0 \\
\hline Workshop & 75 & 0.4 \\
\hline Storage Facility & 19 & 0.1 \\
\hline All & 17099 & 100.0 \\
\hline
\end{tabular}




\section{Longitudinal Dataset}

A separate sample was created aimed at analysing trends of energy use between 2010 and 2016.

A number of steps were taken to exclude buildings which may distort the distribution:

- To avoid double counting, buildings for which DECs were lodged more than once in one year due to renewals that took place in less than one year were excluded from this sample.

- An attempt to create a sample of only those buildings that had lodged DECs on an annual basis for the period intended for analysis was dropped due to a limited number of buildings.

As shown in Figure 1, changes in threshold of DEC scheme is reflected by increases in buildings with smaller sizes appearing from 2013 and 2015. For long term trends, buildings below $1000 \mathrm{~m}^{2}$ in size were excluded to avoid the energy performance of smaller buildings from skewing the distribution in years between 2013 and 2016.

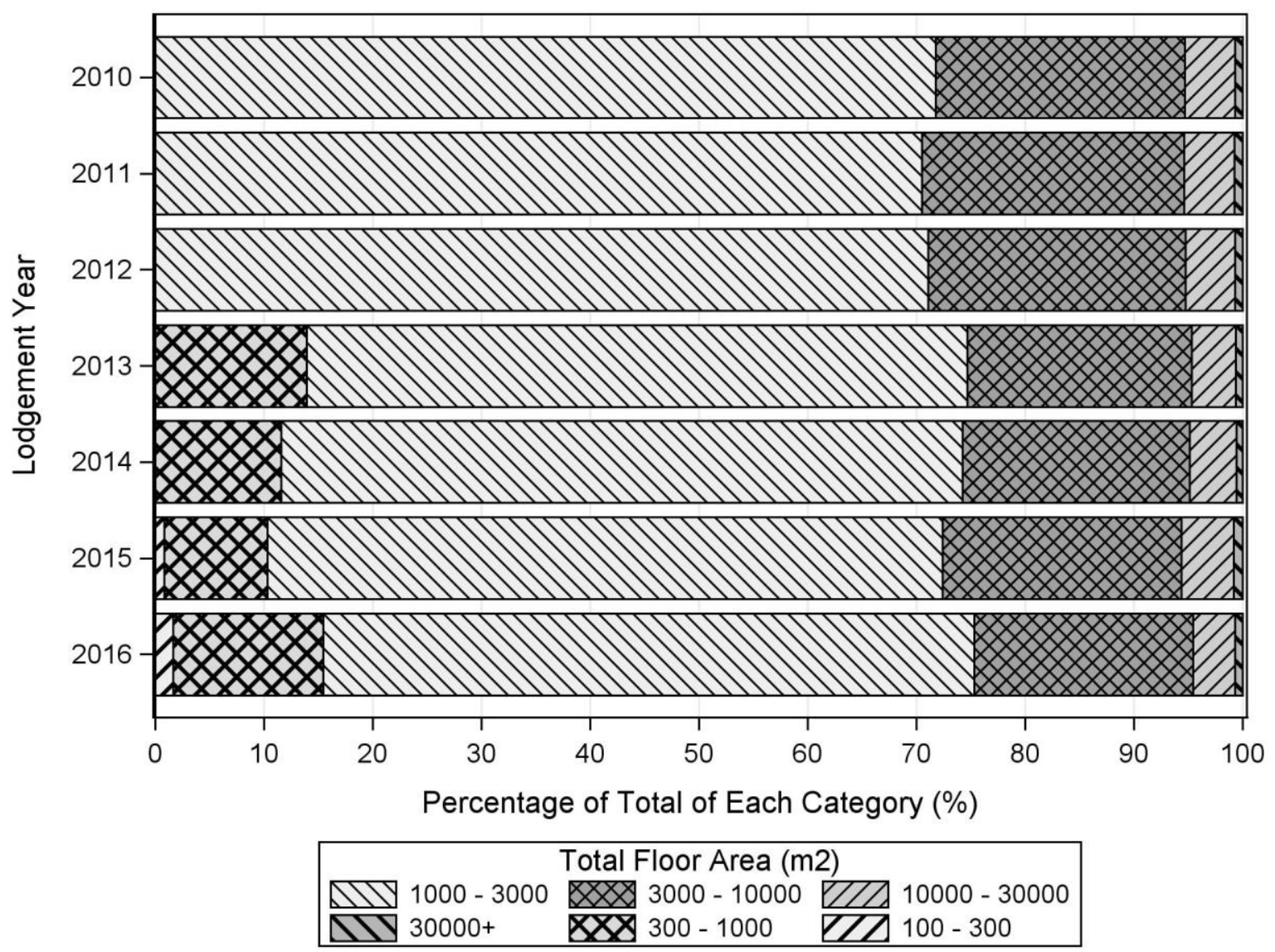

Figure 1 Changing distribution of building floor area by year

Methods of Analysis

For assessing the latest patterns of fossil-thermal EUI, corrections were made to account for the influence of variations in regional and seasonal weather on heating demand. To do so, 
percentages of fossil-thermal EUI outlined in CIBSE TM46 were used to adjust only those proportions that were deemed to be used for space heating in the selected categories. $80 \%$ rather than 55\% was applied to buildings under the 'Schools and Seasonal Public Buildings' category however, based on a previous study (2). Moreover, fossil-thermal EUI was adjusted to the average UK climate of 2021 heating degree days as set out in CIBSE TM46.

Performance ratings that express ratios between measured electrical or fossil-thermal EUI and adjusted (or typical) energy benchmarks were used throughout for comparing the latest patterns of energy use to existing benchmarks. These ratings were produced using the Eq.

(1) shown below:

$$
\text { Performance rating }=\frac{\text { Actual electrical or fossil-thermal EUI }\left(\mathrm{kWh} / \mathrm{m}^{2}\right)}{\text { Adjusted electrical or fossil-thermal benchmarks }\left(\mathrm{kWh} / \mathrm{m}^{2}\right)} \times 100
$$

Using a ratio rather than absolute figures allows the comparison to take into account variation in occupancy hours as well as regional and seasonal variation in weather. This was deemed particularly important for analysing long term trends for which changing weather conditions and occupancy may have influenced the demand for energy.

Box plot function of Statistical Analysis Software (SAS) was used to present and compare distributions of key characteristics of public sector buildings. As shown below in Figure 2, key focus was given to buildings that are within the interquartile range and up to upper and lower fences to avoid losing clarity from far outliers. Note that statistics produced do however include these outliers.

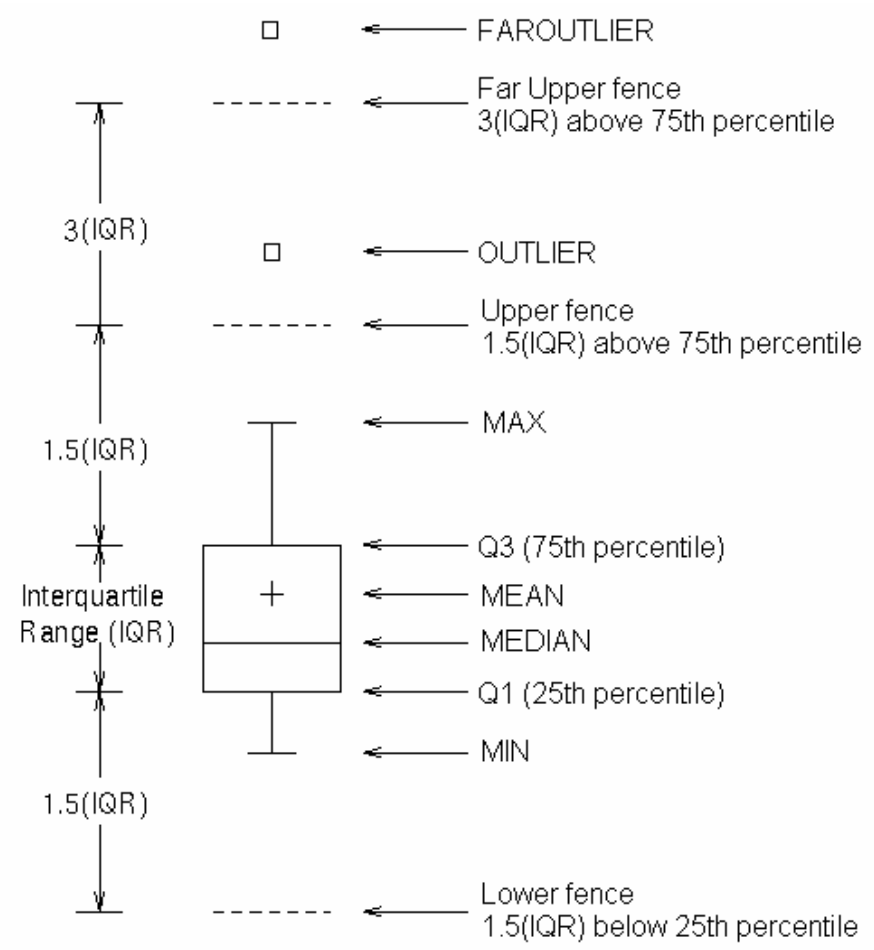

Figure 2 Description of parts of box plot generated by SAS (Source: SAS Institute Inc. 2014)

The relationships between the energy performance of buildings and their characteristics are also assessed. Box plots are used to compare the distribution of electrical and fossil-thermal EUI of buildings grouped by their varying characteristics. The two characteristics included in the DEC data are: 
- Floor area $\left(\mathrm{m}^{2}\right)$

- 'Building Environment' - describes how indoor environment is controlled

In the longitudinal analysis, time series charts plotted using medians rather than average operational ratings from DECs lodged each year to represent a typical performance.

\section{Results}

This section presents results from both cross-sectional and longitudinal analyses of the latest DEC data.

Figure 3 shows the variation in electrical EUI of buildings under each main benchmark category. Note that outliers above and below upper and lower fences, respectively, are not displayed for clarity.

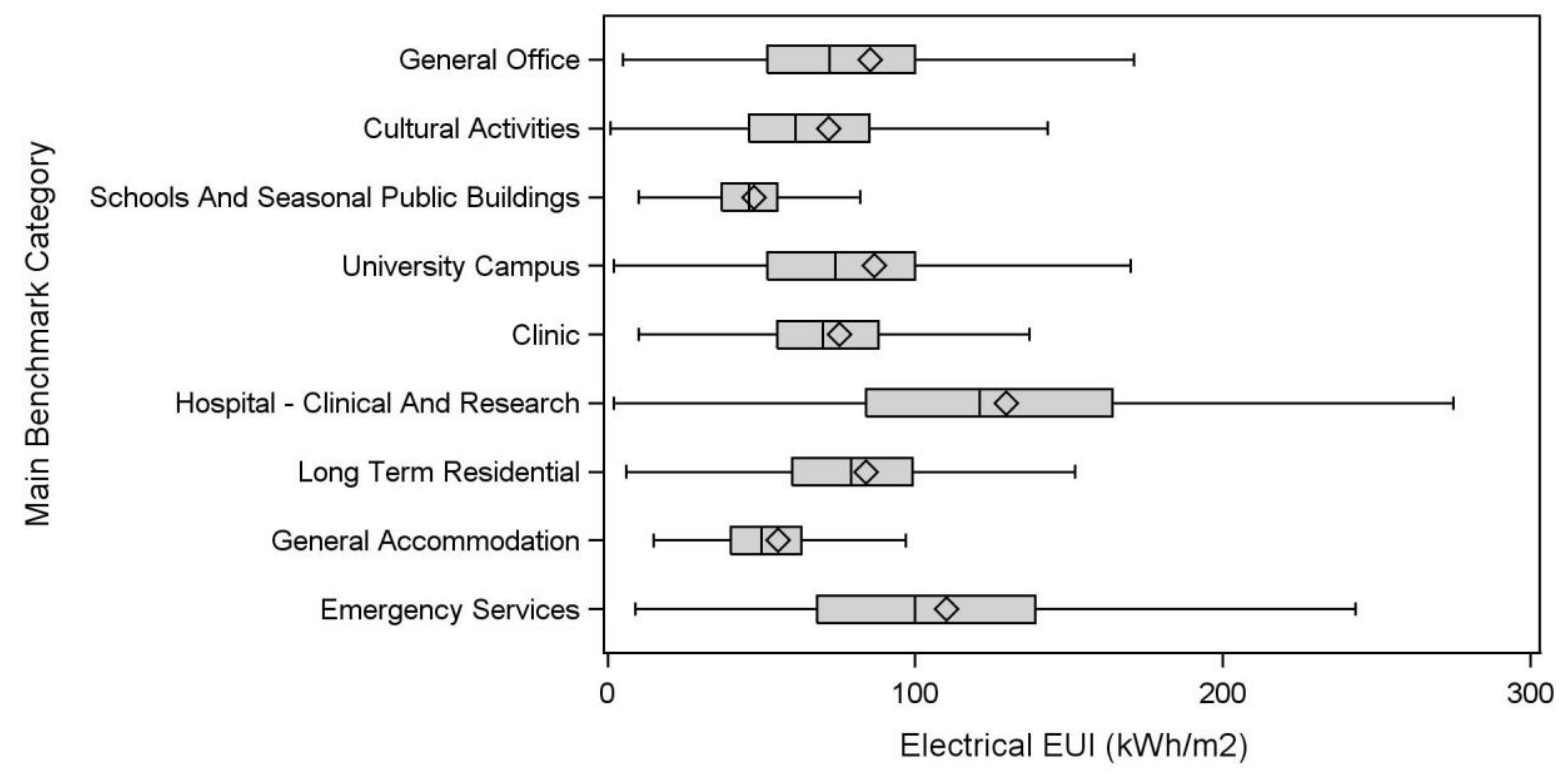

Figure 3 Box plot of electrical EUI of buildings by main benchmark category

Buildings under the 'Hospital - Clinical And Research' category were found to be considerably more intensive in electricity use with a median EUI of $121 \mathrm{kWh} / \mathrm{m}^{2}$ followed by buildings under the 'Emergency Services' with a median consumption figure of $100 \mathrm{kWh} / \mathrm{m}^{2}$. Such intensities are likely due to constant uses of energy-intensive specialist medical equipment in hospitals and, for example, IT systems used in ambulance stations (19). Energy used in these buildings were also found to vary the most which is likely due to a broad range of characteristics of buildings such as building design and age, building services, occupant behaviour, and equipment use and efficiency. Schools and accommodation buildings such as residential halls in higher education institutions were found to be the least intensive in electrical EUI. These buildings were found to vary the least indicating that buildings under these categories are more homogenous than buildings in other categories. Detailed statistics of the distribution can be found in Table 3. 


\begin{tabular}{|c|c|c|c|c|c|c|}
\hline \multirow{2}{*}{ Main Benchmark Category } & \multirow{2}{*}{$\mathbf{N}$} & \multicolumn{5}{|c|}{ Electrical EUI (kWh/m²/yr) } \\
\hline & & $10 \%$ & $25 \%$ & Median & $75 \%$ & $90 \%$ \\
\hline General Office & 1885 & 38 & 52 & 72 & 100 & 139 \\
\hline Cultural Activities & 522 & 32 & 46 & 61 & 85 & 123 \\
\hline Schools And Seasonal Public Buildings & 9864 & 31 & 37 & 46 & 55 & 67 \\
\hline University Campus & 1166 & 35 & 52 & 74 & 100 & 147 \\
\hline Clinic & 825 & 41 & 55 & 70 & 88 & 111 \\
\hline Hospital - Clinical And Research & 363 & 53 & 84 & 121 & 164 & 213 \\
\hline Long Term Residential & 652 & 44 & 60 & 79 & 99 & 125 \\
\hline General Accommodation & 301 & 30 & 40 & 50 & 63 & 85 \\
\hline Emergency Services & 442 & 48 & 68 & 100 & 139 & 181 \\
\hline All & 16020 & & & & & \\
\hline
\end{tabular}

Comparisons of the latest patterns of electrical energy use against existing benchmarks are made in Figure 4. Deviations presented are the differences between actual electrical ratings and CIBSE TM46 benchmarks that represent a rating of 100 .

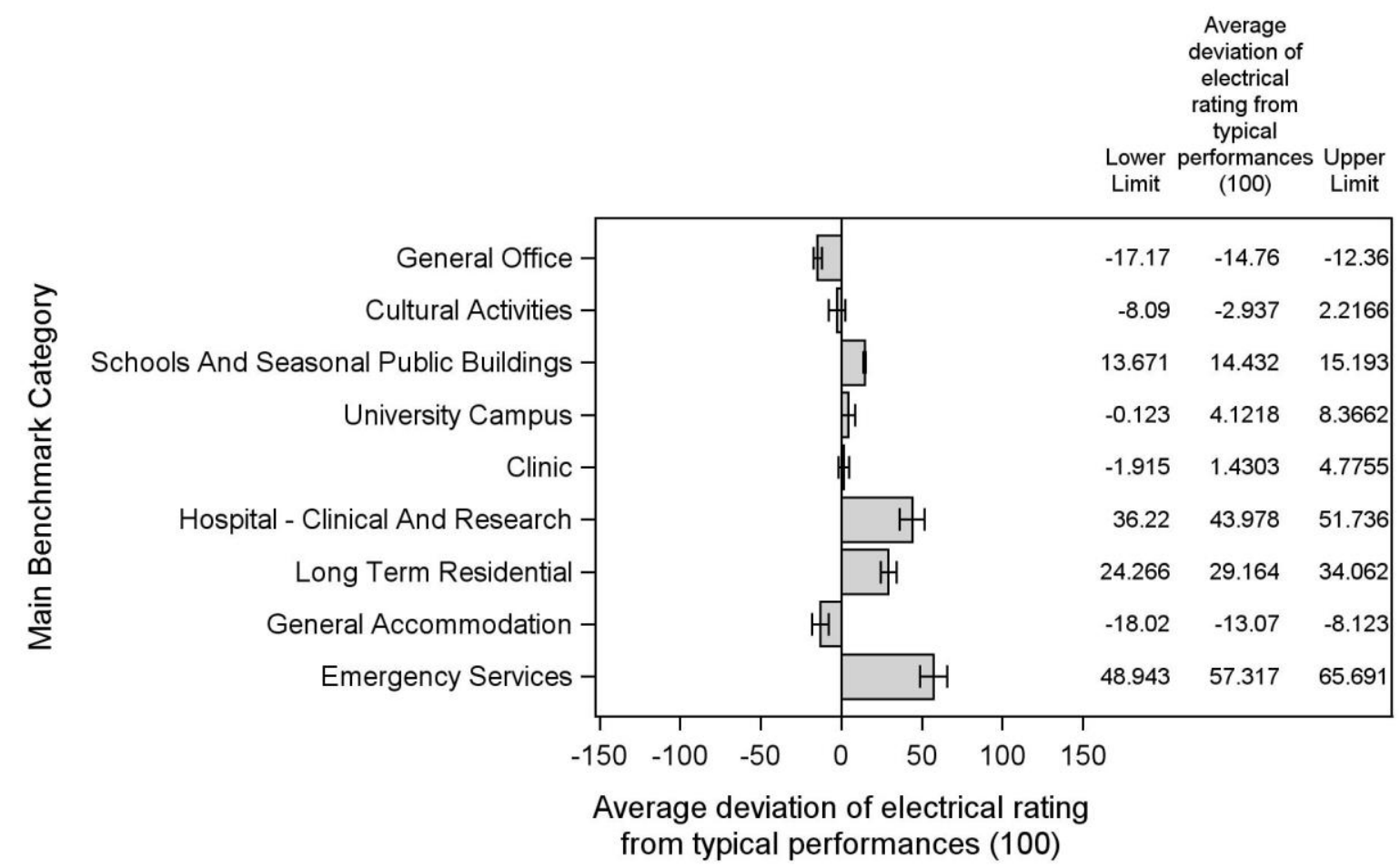

Figure 4 Comparison of electrical operational rating between the latest DEC data and adjusted CIBSE TM46 benchmarks. 95\% confidence interval are displayed at the end of each bar

Buildings in five categories were found to be more intensive on average than the existing benchmarks. Deviations of emergency services buildings such as ambulance, fire and police stations, and hospital buildings were noticeably large suggesting that these buildings are considerably more intensive than anticipated when the benchmarks were developed in 2008 . Buildings under three categories on the other hand were found to be less intensive than the 
benchmarks. Among these were buildings under 'General Office' and 'General Accommodation' which found to have the highest levels of deviations. These deviations suggest that current patterns of electricity of public sector buildings are not likely to be represented accurately by the 'placeholder' benchmarks. Intensity of electricity use of 'University Campus', 'Clinics' and 'Cultural Activities' buildings were found to be very close to the benchmarks suggesting that they remain relevant.

Distribution of weather-corrected thermal EUI of buildings under different categories are shown in Figure 5. Note that outliers above and below upper and lower fences, respectively, are not displayed for clarity.

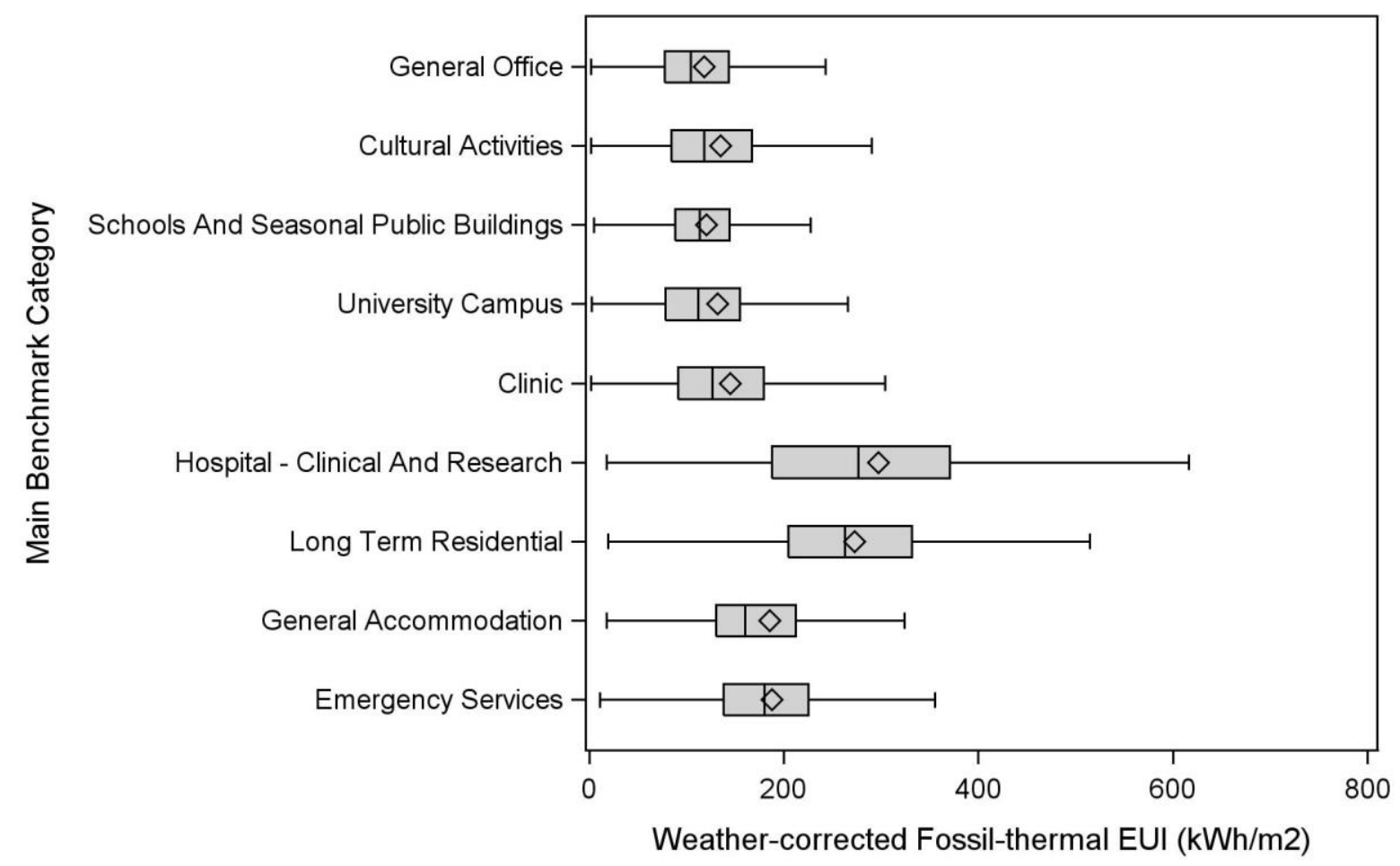

Figure 5 Box plot of weather-corrected fossil-thermal EUI of buildings by main benchmark category. Note that outliers above and below upper and lower fences, respectively, are not displayed for clarity

As shown in Figure 5, hospital buildings were found to be the most intensive users of heating energy with a median figure of $277 \mathrm{kWh} / \mathrm{m}^{2}$. Although not directly comparable, comparing the figure against typical energy benchmarks in CIBSE Guide $F$ for a range of hospitals that range between $411 \mathrm{kWh} / \mathrm{m}^{2}$ and $518 \mathrm{kWh} / \mathrm{m}^{2}$ suggests that these buildings are considerably less intensive than what was perceived to be typical back when these benchmarks were published. Office buildings on the other hand were found to be the least intensive in terms of heating energy use with a median of $105 \mathrm{kWh} / \mathrm{m}^{2}$, which was considerably less than benchmarks in CIBSE Guide $F$ for a range of office archetypes shown that ranged between $151 \mathrm{kWh} / \mathrm{m}^{2}$ and $210 \mathrm{kWh} / \mathrm{m}^{2}$. Detailed statistics of the distribution can be found in Table 4. 


\begin{tabular}{|c|c|c|c|c|c|c|}
\hline \multirow[t]{2}{*}{ Main Benchmark Category } & \multirow[t]{2}{*}{$\mathbf{N}$} & \multicolumn{5}{|c|}{$\begin{array}{c}\text { Weather-corrected Fossil-thermal } \\
\text { EUI (kWh/m²/yr) }\end{array}$} \\
\hline & & $10 \%$ & $25 \%$ & Median & $75 \%$ & $90 \%$ \\
\hline General Office & 1885 & 53 & 77 & 105 & 144 & 197 \\
\hline Cultural Activities & 522 & 60 & 84 & 119 & 167 & 220 \\
\hline Schools And Seasonal Public Buildings & 9864 & 70 & 89 & 114 & 144 & 178 \\
\hline University Campus & 1166 & 53 & 78 & 112 & 155 & 226 \\
\hline Clinic & 825 & 64 & 92 & 126 & 180 & 246 \\
\hline Hospital - Clinical And Research & 363 & 140 & 188 & 277 & 370 & 461 \\
\hline Long Term Residential & 652 & 152 & 205 & 263 & 332 & 418 \\
\hline General Accommodation & 301 & 82 & 130 & 160 & 212 & 273 \\
\hline Emergency Services & 442 & 102 & 138 & 180 & 225 & 280 \\
\hline All & 16020 & & & & & \\
\hline
\end{tabular}

Figure 6 presents a comparison of fossil-thermal ratings to the existing energy benchmarks for a more accurate assessment of their representativeness.

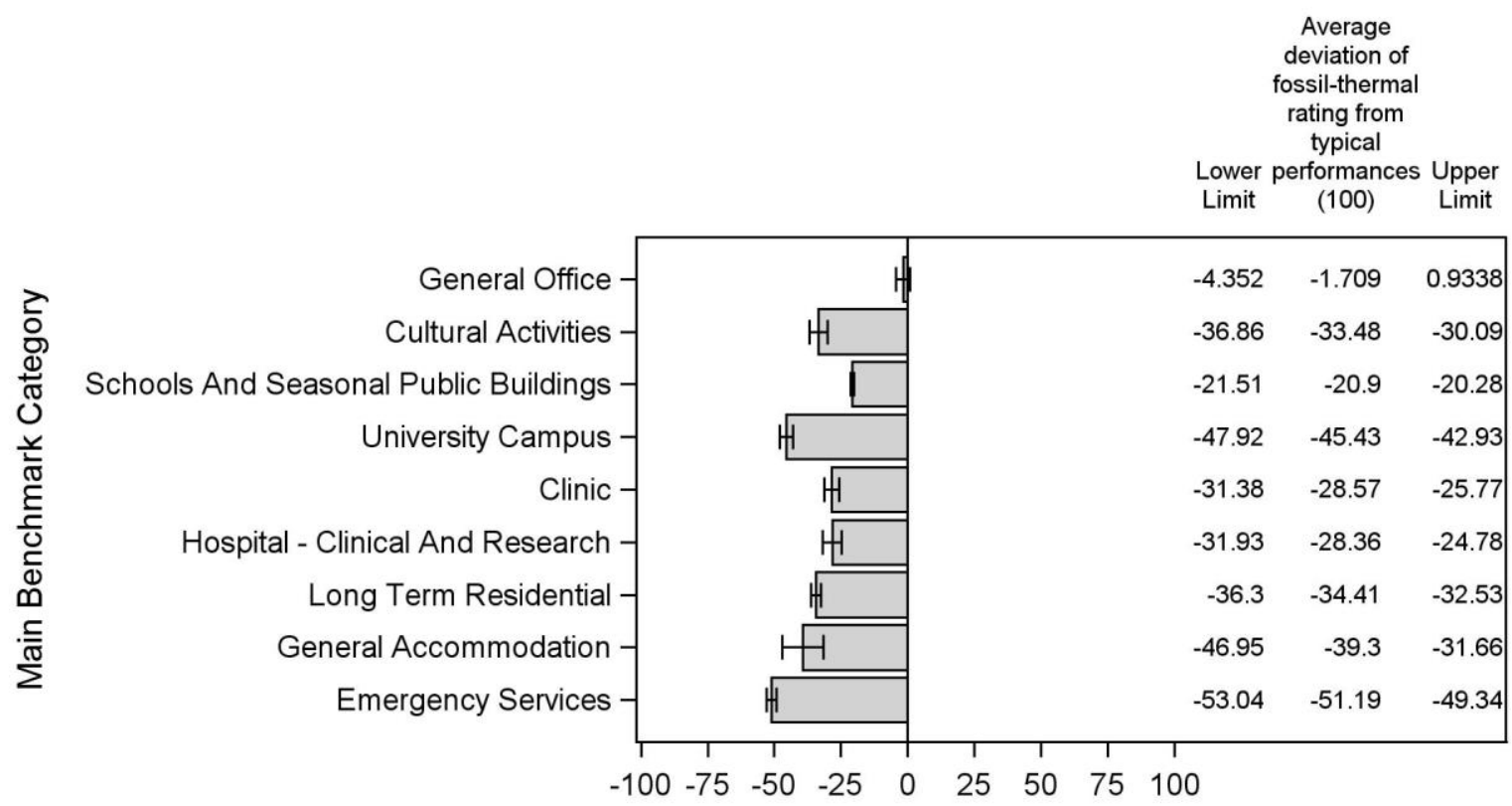

Average deviation of fossil-thermal rating from typical performances

(100)

Figure 6 Comparison of fossil-thermal rating between the latest DEC data and adjusted CIBSE TM46 benchmarks. 95\% confidence interval are displayed at the end of each bar.

As shown in Figure 6, average deviation in all categories were found to be below the typical energy benchmarks. The differences were noticeable in eight out of 9 categories with mean values ranging between -20 for schools to -51 for 'Emergency Services' category. These differences suggest that patterns of heating energy use in the stock likely to be considerably lower than that suggested by the benchmarks. The average deviation for the 'General 
Offices' category on the other hand was found to deviate very little from the CIBSE TM46 benchmarks with equally small variation suggesting that they remain reasonably relevant. The large discrepancies observed between the actual EUI and the typical benchmarks in most categories point to the fact that these values should be used with caution when assessing operational efficiency of heating energy use.

The following section provides an overview of the key characteristics of public sector buildings under different categories. Figure 7 shows distribution of total floor area. Note that the figure only displays records that fall within upper and lower fences, as described in Figure 2, for legibility.

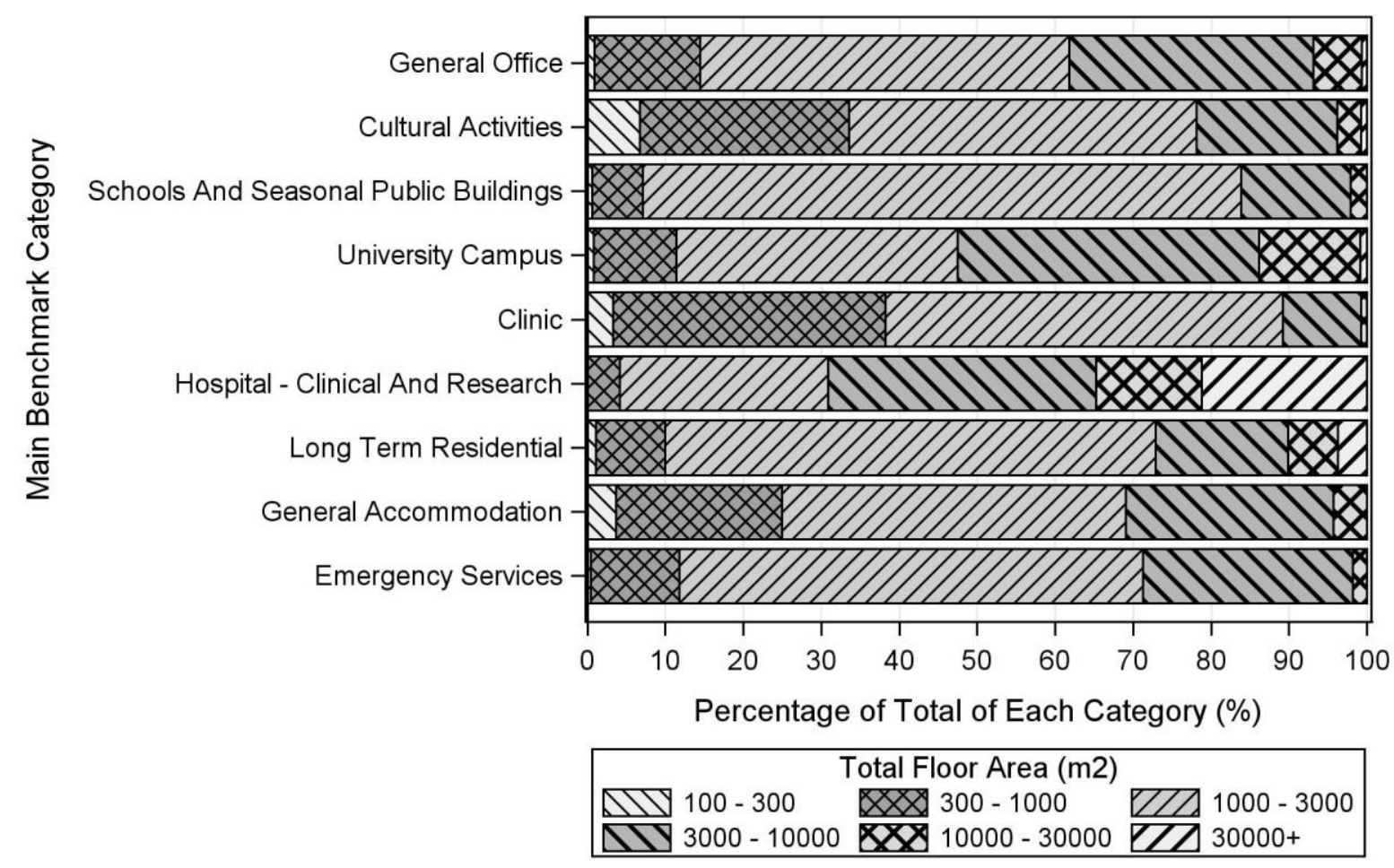

Figure 7 Distribution of floor area of buildings (or sites) in each benchmark category

As shown in Figure 7, there is a wide variation in sizes of buildings across benchmark categories. At the lower end of the spectrum, it can be seen that proportion of buildings that are between 100 and $300 \mathrm{~m}^{2}$ is noticeably low at less than $4 \%$ of buildings in any category. Considering that the threshold for DECs was lowered to $250 \mathrm{~m}^{2}$ in 2015 , the lower proportion may suggest that there are not many buildings that are this small, at least not in the public sector (20). In contrast, there are categories that have extremely large buildings. 'Hospital Clinical And Research' category for example has the highest proportion (16\%) of buildings that exceed $30,000 \mathrm{~m}^{2}$ where an infirmary was reported to be above $200,000 \mathrm{~m}^{2}$. Some part of the wide variability in size is likely to be attributable to the aggregated nature of the classification of buildings under the DEC scheme, and would require considerable efforts to interrogate by sub-activity without availability of the building type classification variable (16). Such differences between sizes would also have implications on key characteristics of buildings that influence their energy performance such as the level of servicing, operational efficiency, and occupant behaviour. 
Figure 8 shows variations in electrical EUI of buildings under each benchmark category by floor area.

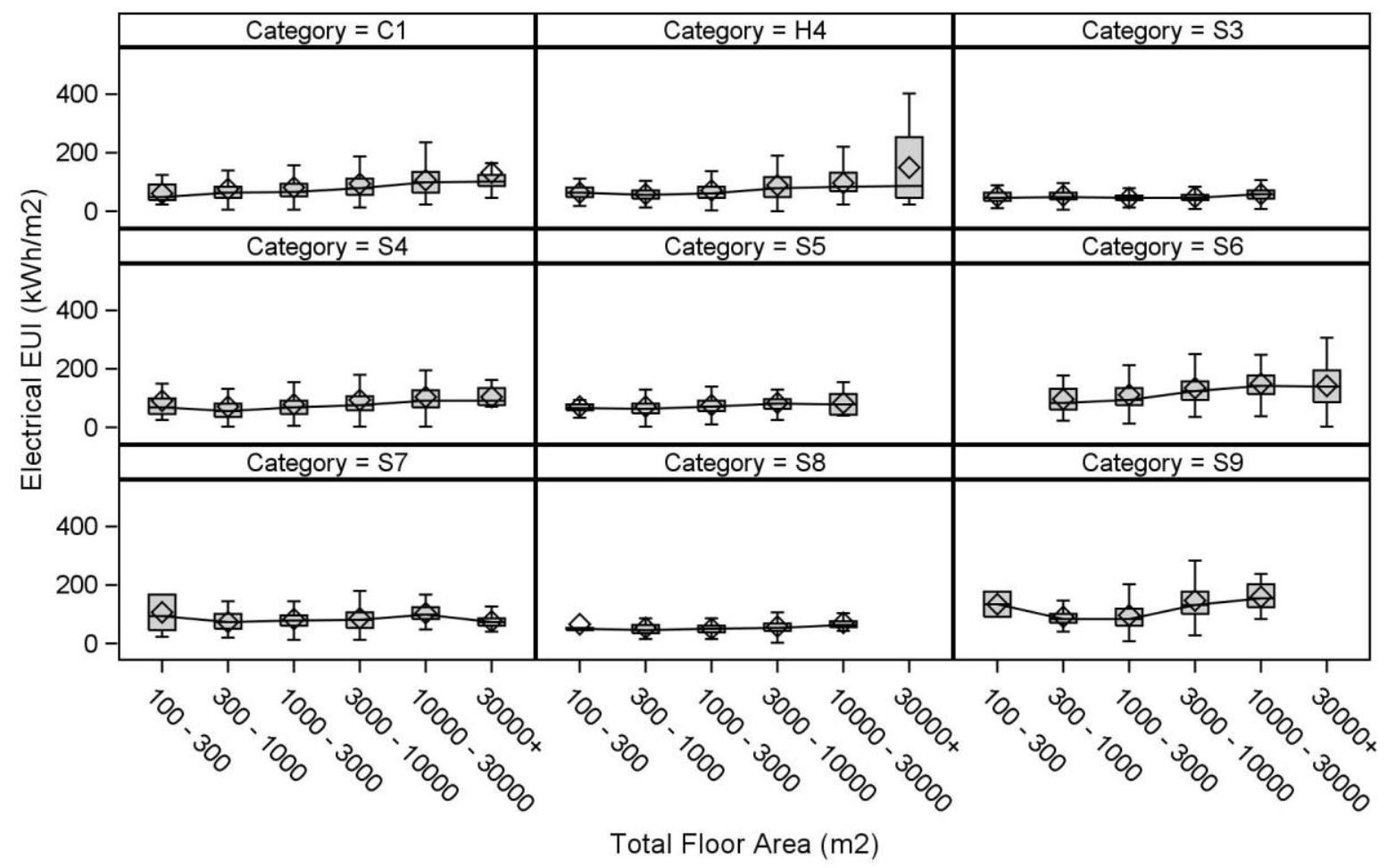

Figure 8 Distribution of electrical EUI by floor area for each main benchmark category $(C 1=$ General Office, H4 = Cultural Activities, S3 = Schools And Seasonal Public Buildings, S4 = University Campus, S5 = Clinic, S6 = Hospital - Clinical And Research, S7 = Long Term Residential, S8 = General Accommodation, S9 = Emergency Services)

In many categories, larger buildings tend to be more intensive in terms of electrical EUI. Buildings under 'Emergency Services' (S9) and 'General Office' (C1) categories in particular show a clear and gradual increase in intensity in line with increasing floor area. Such pattern is likely due to differences in activities of organisations of varying sizes and additional facilities required. Despite categorised under the same category, large central government offices may, for example, need electrically intensive facilities such as server rooms for storing and processing data at national level as opposed to smaller local authority offices that may have a different requirement.

The pattern is less clear for fossil-thermal fuel (Figure 9). Unlike electrical EUI, most categories showed extremely small differences in EUI across the floor area bands. Buildings under 'General Office' (C1), 'Cultural Activities' (H4) and 'Schools And Seasonal Public Buildings' (S3) categories, however, showed a gradually decreasing intensity of heating energy use as buildings became larger in floor area. Such pattern is likely due to increased levels of energy efficiency owing to reduced exposed surface area compared to internal volume. Heating consumption of hospital buildings (S6) on the other hand were found to increase in intensity as buildings become larger. Closer inspection of records showed that small buildings in this category tended to be small local hospitals or parts of hospitals that are not likely to have heating intensive facilities such as catering and accommodation. Large hospital complexes on the other hand tend to require such facilities to support a much wider range of activities and accommodate a large number of occupants (21). 


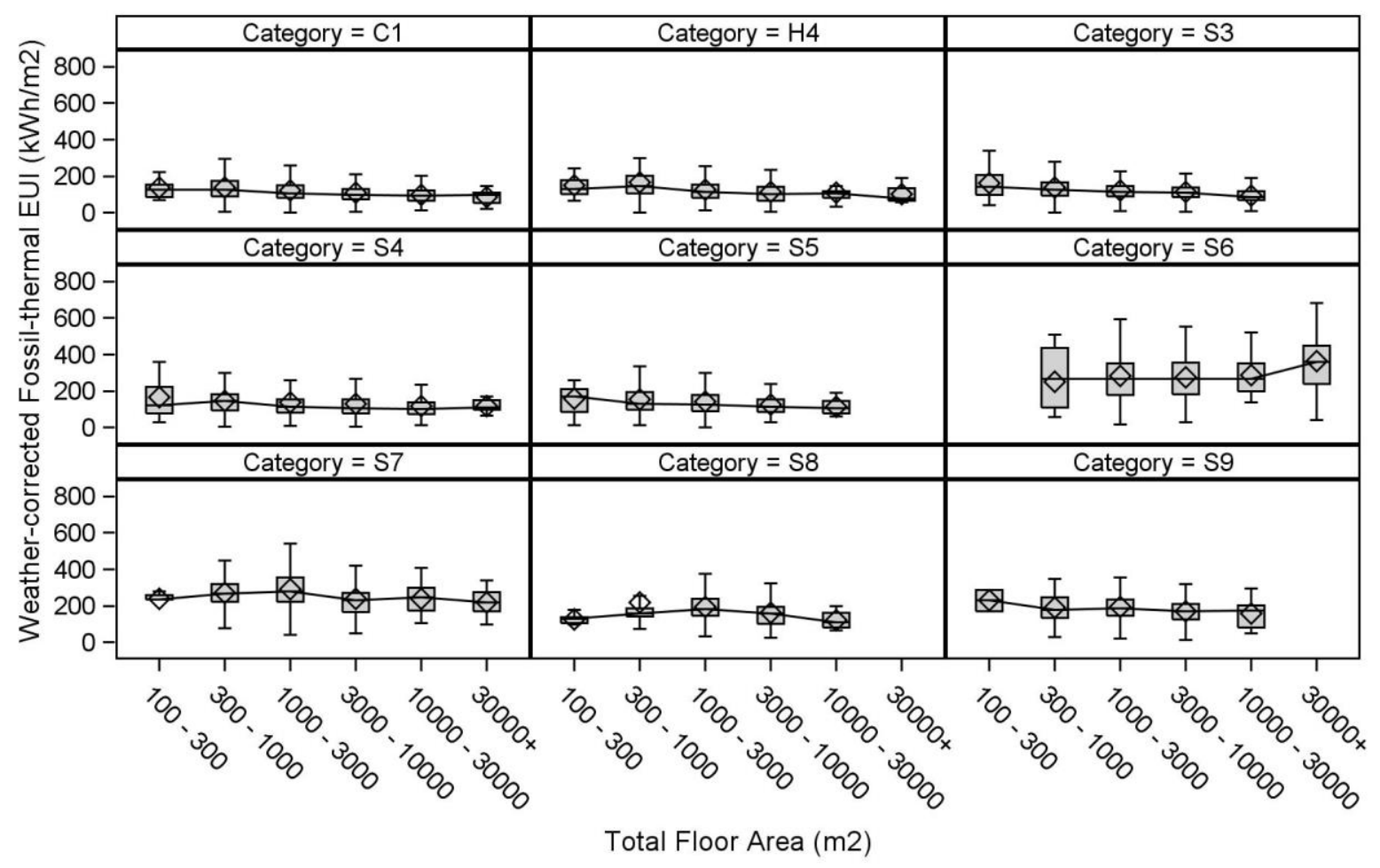

Figure 9 Distribution of weather-corrected EUI by floor area for each main benchmark category

Figure 10 provides variations in percentages of buildings with different conditioning strategies. Note that the analysis is based on the classification system used to describe a range of predominant servicing strategies for conditioning indoor environment under the DEC scheme.

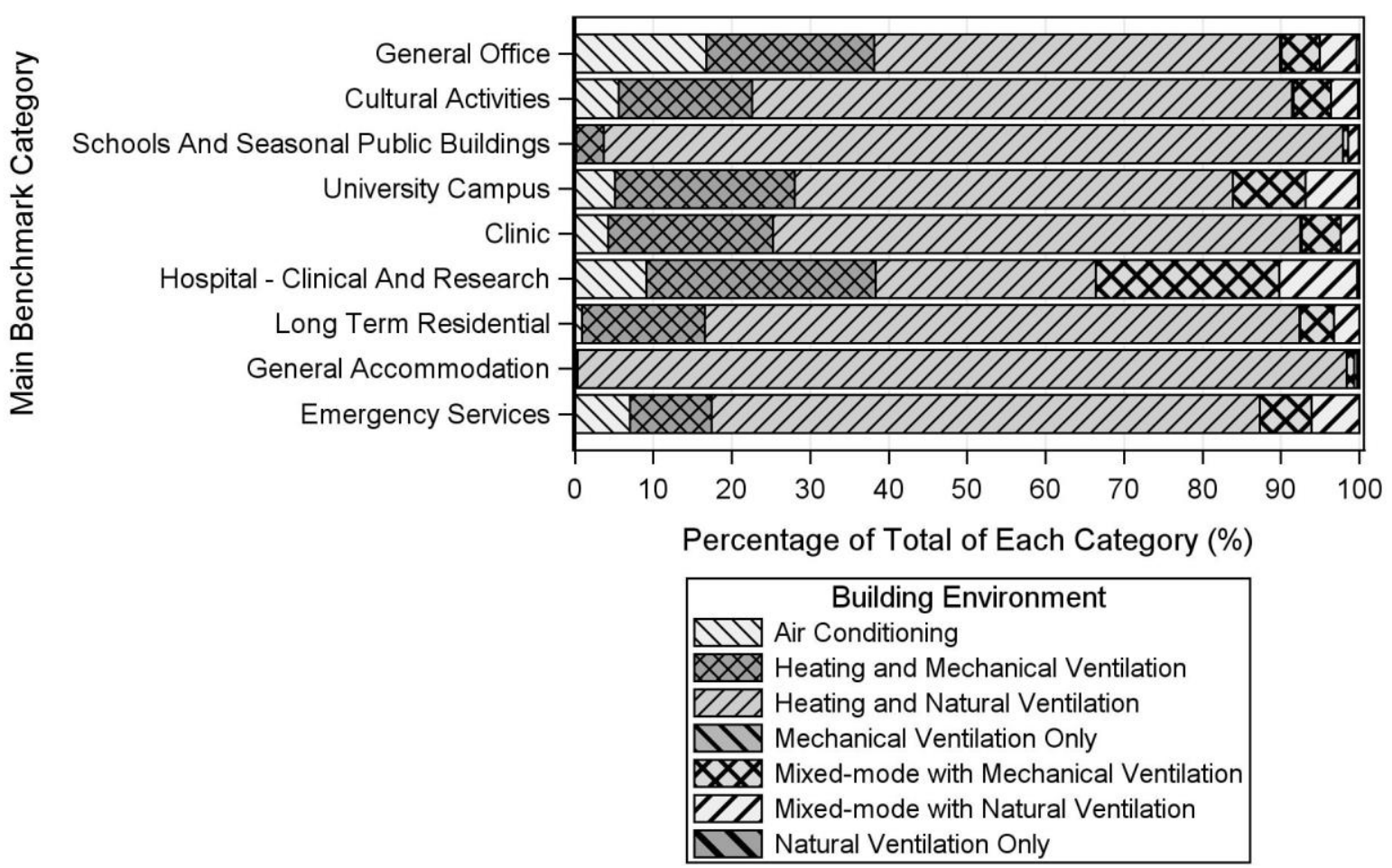

Figure 10 Distribution of conditioning strategies in buildings by main benchmark category 
As one would expect in England and Wales, a large proportion of buildings in many benchmark categories were found to use natural ventilation as the main mode of conditioning the indoor environment. Buildings under 'General Accommodation', which tended to be student halls of universities, and 'Schools and Seasonal Public Buildings' categories were found to have the highest percentages of predominantly naturally ventilated buildings at approximately $97 \%$ and $94 \%$ respectively. Proportion of buildings that employ mechanical means were much higher in 'Hospitals - Clinical and Research' that have more strict requirements to maintain the indoor environment healthy and comfortable.

Figure 11 shows variations in electrical EUI of buildings across benchmark categories with varying levels of mechanical systems used for conditioning the indoor environment. Note that for clarity and due to very small sample sizes, buildings reported to employ 'Natural Ventilation Only' and 'Mechanical Ventilation Only' were excluded from the chart.

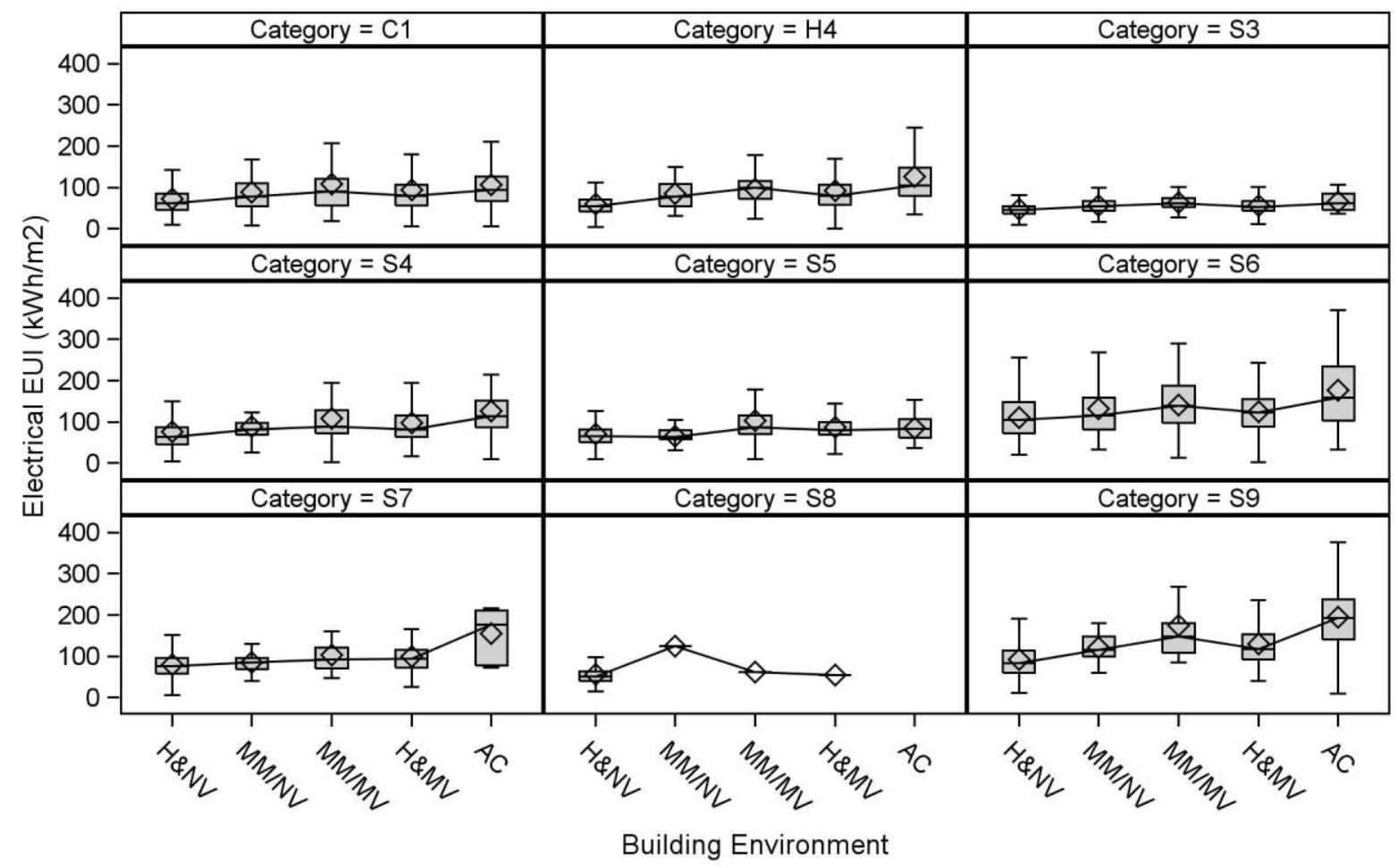

Figure 11 distribution of electrical EUI of buildings by building environment and category (H\&NV = Heating and Natural Ventilation, MM/NV = Mixed-mode with Natural Ventilation, MM/MV = Mixed-mode with Mechanical Ventilation, $H \& M V=$ Heating and Mechanical Ventilation, $A C=$ Air Conditioning)

Figure 11 shows that electrical EUI gradually increases in most categories as buildings become more heavily serviced by mechanical systems. Taking buildings under the 'University Campus' (S4) category, for example, variation in EUI in each category appears similar whilst median increases from $64 \mathrm{kWh} / \mathrm{m}^{2}$ in predominantly naturally ventilated buildings up to $113 \mathrm{kWh} / \mathrm{m}^{2}$ in predominantly air-conditioned buildings (Table 5 ). Across the categories, air-conditioned buildings were found to be $43 \%$ more intensive on average in terms of electrical energy use than naturally ventilated buildings. Buildings under 'General Accommodation' on the other hand did not show a clear pattern in relation to varying levels of mechanical systems. What is also worth noting is the wider variation in EUI of buildings that are air-conditioned. This could be due to the variations in floor areas that are air- 
conditioned between buildings as well as varying energy efficiency levels based on controls and maintenance.

\begin{tabular}{|c|c|c|c|c|c|c|}
\hline \multirow{3}{*}{ Main Benchmark Category } & \multirow{3}{*}{$\mathbf{N}$} & \multicolumn{5}{|c|}{$\begin{array}{c}\text { Electrical EUI }\left(\mathrm{kWh} / \mathrm{m}^{2}\right) \text { by Building } \\
\text { Environment }\end{array}$} \\
\hline & & H\&NV & $\mathrm{MM} / \mathrm{NV}$ & MM/MV & H\&MV & AC \\
\hline & & Median & Median & Median & Median & Median \\
\hline General Office & 1875 & 62 & 78 & 90 & 79 & 94 \\
\hline Cultural Activities & 520 & 54 & 78 & 99 & 80 & 104 \\
\hline Schools And Seasonal Public Buildings & 9855 & 45 & 55 & 61 & 53 & 62 \\
\hline University Campus & 1164 & 64 & 81 & 88 & 82 & 113 \\
\hline Clinic & 823 & 65 & 64 & 87 & 80 & 83 \\
\hline Hospital - Clinical And Research & 362 & 104 & 116 & 139 & 123 & 158 \\
\hline Long Term Residential & 651 & 76 & 85 & 92 & 94 & 177 \\
\hline General Accommodation & 300 & 50 & 124 & 62 & 54 & \\
\hline Emergency Services & 442 & 83 & 115 & 147 & 118 & 193 \\
\hline
\end{tabular}

Figure 12 shows variations in weather-corrected fossil-thermal EUI of buildings across benchmark categories with varying levels of mechanical systems for conditioning the indoor environment. Note that for clarity and due to very small sample sizes, buildings that reported 'Natural Ventilation Only' and 'Mechanical Ventilation Only' were excluded from the chart.

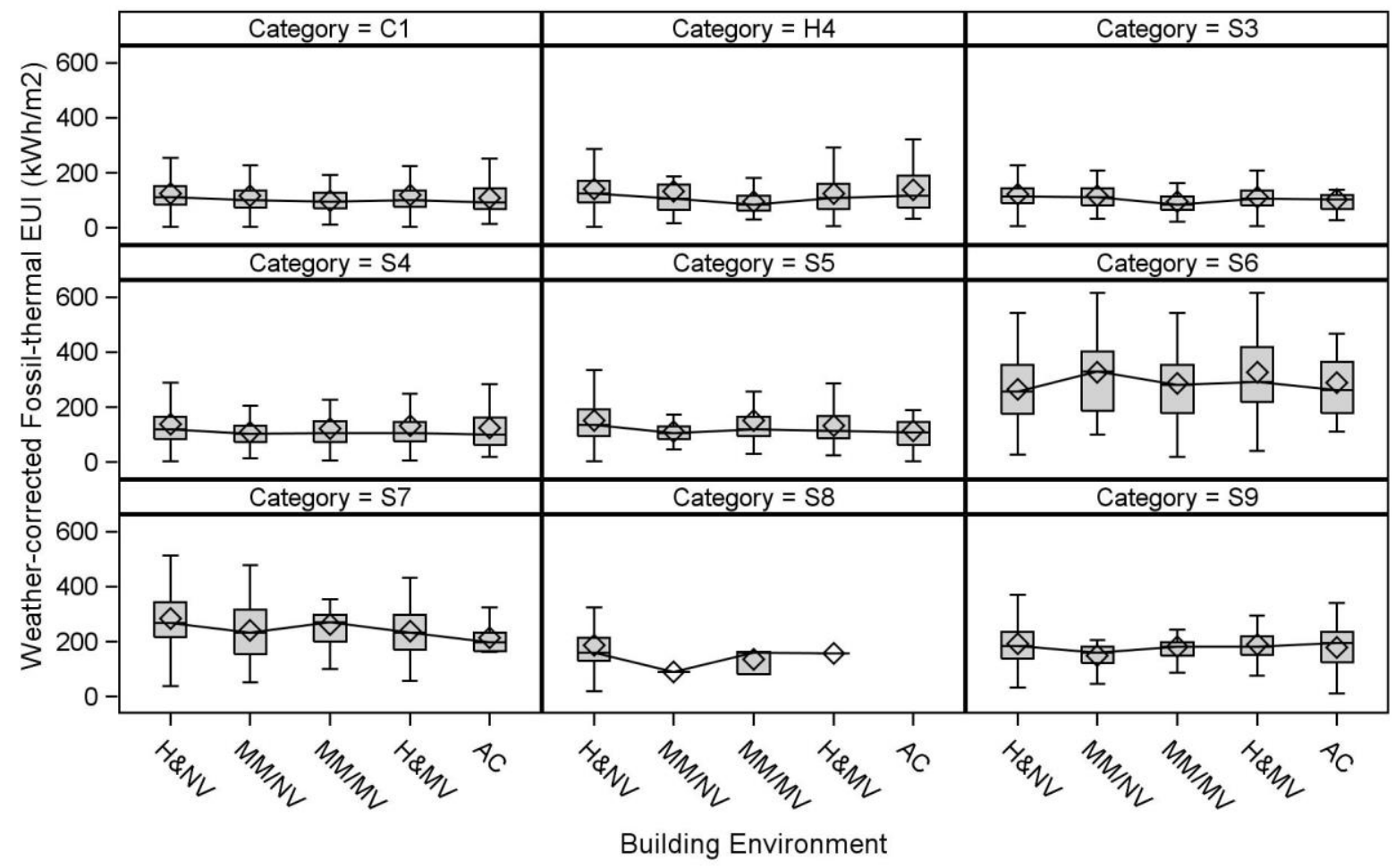

Figure 12 distribution of weather-corrected fossil-thermal EUI of buildings by building environment and category 
Across categories, variations in fossil-thermal EUI by building environment are generally similar without a clear pattern. Looking at the differences in medians however air-conditioned buildings in seven out of nine categories tended to be less intensive in fossil-thermal energy use than naturally ventilated buildings. The difference was found to vary between $7 \%$ and $27 \%$ with an average of $15 \%$ in these categories. These findings suggest that mechanically ventilated buildings, which have greater control over heat loss via ventilation and likely to be built to higher standards, are generally performing better than their naturally ventilated counterparts.

Table 6 Median weather-corrected fossil-thermal EUI of buildings by building environment type

\begin{tabular}{|c|c|c|c|c|c|c|}
\hline \multirow[t]{2}{*}{ Main Benchmark Category } & \multirow[t]{2}{*}{$\mathbf{N}$} & \multicolumn{5}{|c|}{$\begin{array}{l}\text { Median Weather-corrected Fossil-thermal EUI } \\
\left(\mathrm{kWh} / \mathrm{m}^{2}\right) \text { by Building Environment }\end{array}$} \\
\hline & & $H \& N V$ & MM/NV & MM/MV & H\&MV & $\mathrm{AC}$ \\
\hline General Office & 1875 & 111 & 100 & 95 & 101 & 93 \\
\hline Cultural Activities & 520 & 126 & 106 & 85 & 108 & 117 \\
\hline Schools And Seasonal Public Buildings & 9855 & 114 & 111 & 85 & 105 & 103 \\
\hline University Campus & 1164 & 118 & 103 & 106 & 105 & 101 \\
\hline Clinic & 823 & 134 & 105 & 120 & 113 & 108 \\
\hline Hospital - Clinical And Research & 362 & 256 & 330 & 282 & 292 & 261 \\
\hline Long Term Residential & 651 & 269 & 231 & 270 & 233 & 197 \\
\hline General Accommodation & 300 & 161 & 89 & 160 & 157 & \\
\hline Emergency Services & 442 & 184 & 158 & 181 & 181 & 196 \\
\hline
\end{tabular}

Figure 13 shows a time series chart of the ratio between actual electrical EUI and adjusted electrical benchmarks. The plot shows median ratings observed between 2010 and 2016 by main benchmark category. 


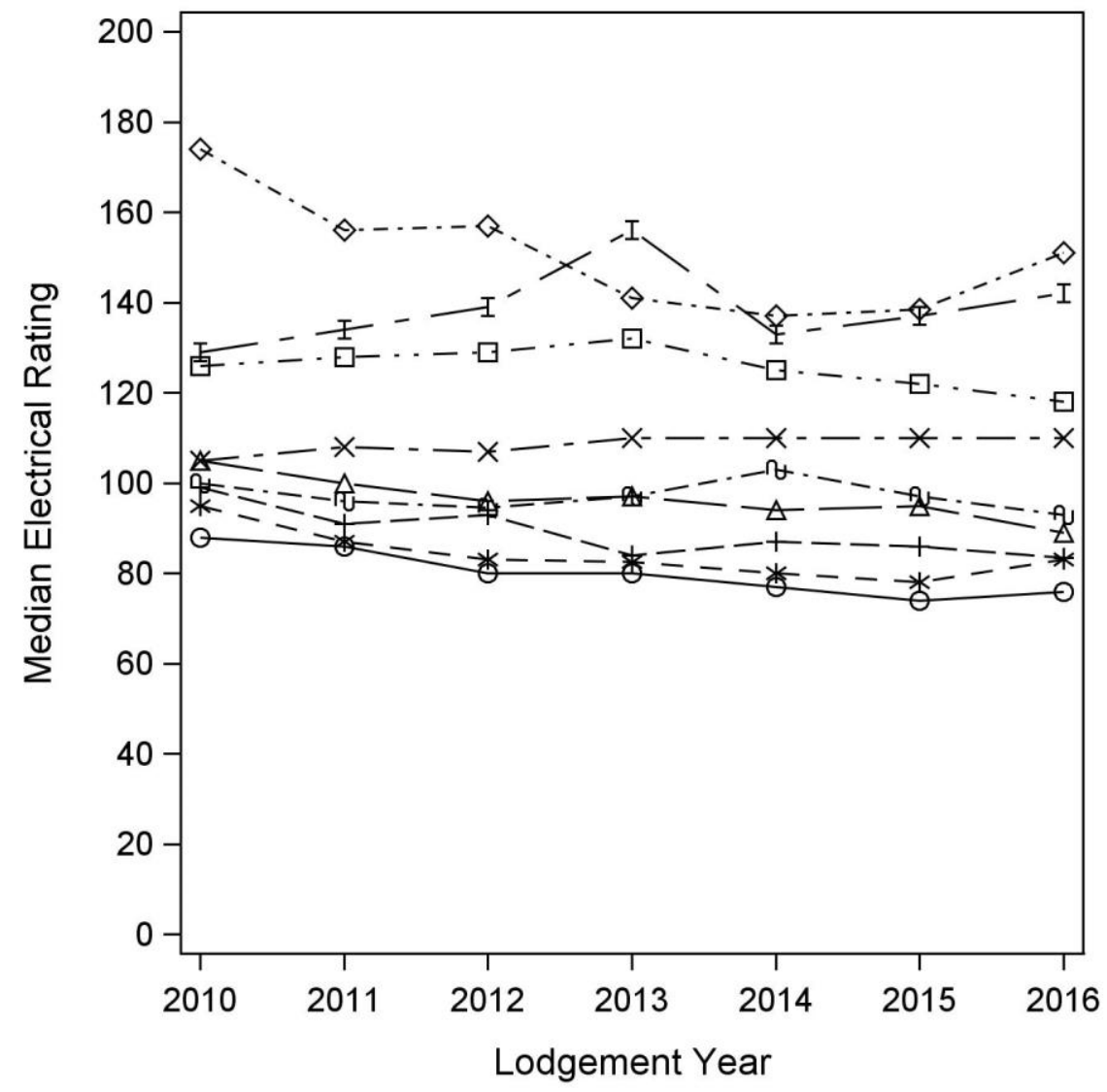

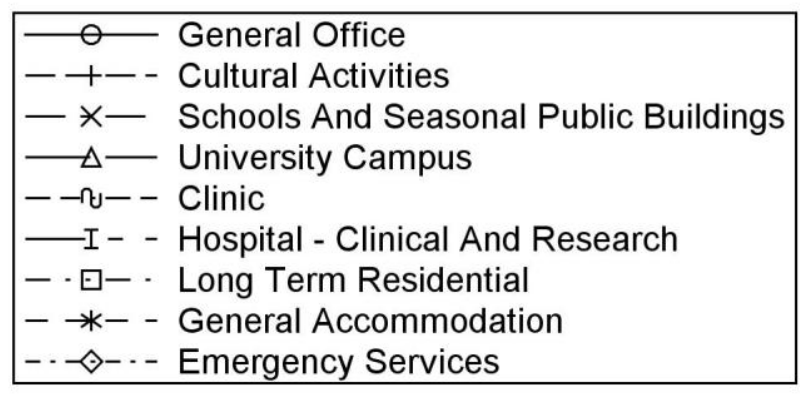

Figure 13 Changes in patterns of electrical energy use of selected non-domestic buildings between 2010 and 2016

There are many categories such as 'General Office' and 'University Campus' that show a gradual downward trend over the seven-year period. This shows that buildings under these categories have become less intensive in electrical energy consumption. There are numerous factors that may have contributed to such trends such as, for example, changes in public sector employment, improvements in energy efficiency and the impact of economic downturn. Taking the employment for example, historical changes in public sector employment was found to decrease gradually over the same period from 6.4 million in March 2010 to 5.4 million in March 2016 (22). This equates to approximately 15\% decrease in the workforce which closely resembles the overall change in electrical rating of 'General Office' buildings of $14 \%$ (Table 7 ).

A gradual increase in electrical consumption on the other hand was observed in 'Schools and Seasonal Public Buildings' category over the same period. Electrical rating of schools 
was found to increase by $5 \%$ over the seven-year period despite the gradual decrease in number of pupils over the same period from 24,616 in 2010 to 24,288 in 2016 . This also indicates that trends observed from previous studies has continued until recent years $(12,13)$. Such trend is likely to be due to a growing uptake of ICT equipment for providing, for example, virtual learning environments (23). Since 2014, however, the intensity appears to have remained unchanged which may indicate a possibility of the energy use peaking in schools.

Buildings under 'Hospital - Clinical and Research' on the other hand showed a clear increasing trend with an overall increase of $10 \%$ over the same period. This is particularly concerning as much of the electricity used in hospitals is attributed to increased uses of specialist medical equipment that are currently not regulated in the UK (19). The clear and gradual increase in electrical intensity in hospitals also suggests that the trend could continue in the near future. Similarly, emergency services buildings such as police and fire stations have shown signs that electricity consumption could increase in the following years.

Table 7 Year-on-year percentage changes in median electrical rating of buildings in each benchmark category

\begin{tabular}{lcccccccc}
\hline \multirow{2}{*}{ Main Benchmark Category } & \multicolumn{9}{c}{ Year-on-Year Changes in Median Electrical Rating (\%) } \\
& 2010 & 2011 & 2012 & 2013 & 2014 & 2015 & 2016 & Overall \\
\hline General Office & - & $-2 \%$ & $-7 \%$ & $0 \%$ & $-4 \%$ & $-4 \%$ & $3 \%$ & $-14 \%$ \\
Cultural Activities & - & $-8 \%$ & $2 \%$ & $-10 \%$ & $4 \%$ & $-1 \%$ & $-3 \%$ & $-16 \%$ \\
Schools And Seasonal Public Buildings & - & $3 \%$ & $-1 \%$ & $3 \%$ & $0 \%$ & $0 \%$ & $0 \%$ & $5 \%$ \\
University Campus & - & $-5 \%$ & $-4 \%$ & $1 \%$ & $-3 \%$ & $1 \%$ & $-6 \%$ & $-15 \%$ \\
Clinic & - & $-4 \%$ & $-2 \%$ & $3 \%$ & $6 \%$ & $-6 \%$ & $-4 \%$ & $-7 \%$ \\
Hospital - Clinical And Research & - & $-4 \%$ & $4 \%$ & $12 \%$ & $15 \%$ & $3 \%$ & $4 \%$ & $10 \%$ \\
Long Term Residential & - & $2 \%$ & $1 \%$ & $2 \%$ & $-5 \%$ & $-2 \%$ & $-3 \%$ & $-6 \%$ \\
General Accommodation & - & $-8 \%$ & $-5 \%$ & $-1 \%$ & $-3 \%$ & $-3 \%$ & $6 \%$ & $-13 \%$ \\
Emergency Services & - & - & & & & & & \\
& $-10 \%$ & $1 \%$ & $-10 \%$ & $-3 \%$ & $1 \%$ & $9 \%$ & $-13 \%$ \\
\hline
\end{tabular}

Figure 14 shows a time series chart of the ratio between actual fossil-thermal EUI and adjusted fossil-thermal benchmarks. The plot shows median ratings observed between 2010 and 2016 for each main benchmark category. 


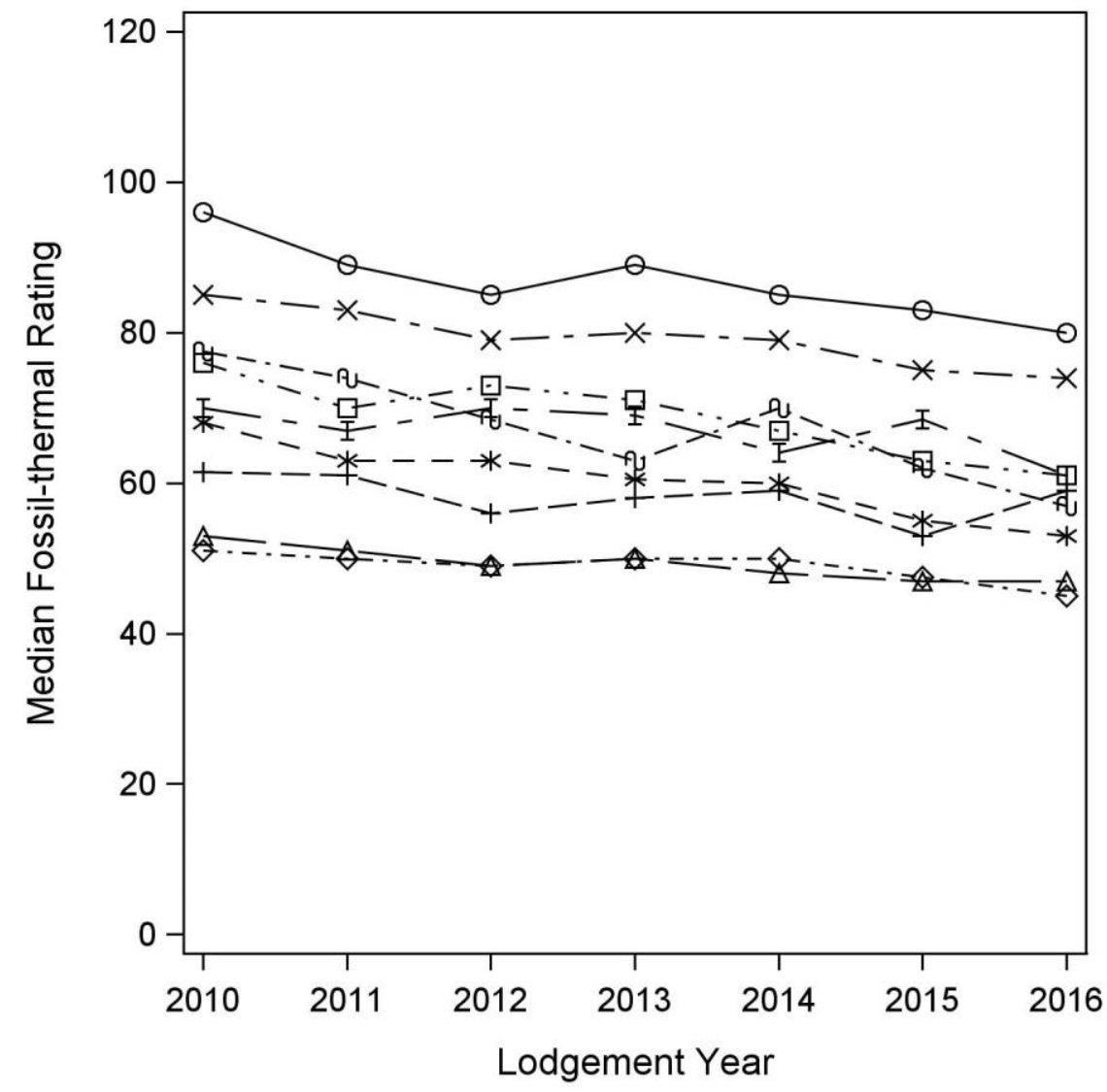

\begin{tabular}{|c|c|}
\hline 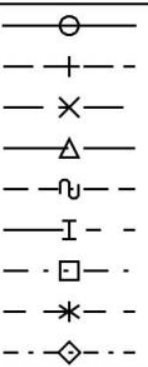 & $\begin{array}{l}\text { General Office } \\
\text { Cultural Activities } \\
\text { Schools And Seasonal Public Buildings } \\
\text { University Campus } \\
\text { Clinic } \\
\text { Hospital - Clinical And Research } \\
\text { Long Term Residential } \\
\text { General Accommodation } \\
\text { Emergency Services }\end{array}$ \\
\hline
\end{tabular}

Figure 14 Changes in patterns of fossil-thermal energy use of selected non-domestic buildings between 2010 and 2016

As shown in Figure 14, a general downward trend is observed across all categories with a $15 \%$ decrease in fossil-thermal rating on average between 2010 and 2016 . Buildings under the 'Cultural Activities' category were found to have changed the least with an overall decrease of $4 \%$, and did not show a clear trend. The rating of 'Clinics' buildings on the other hand were found to change the most with $26 \%$ overall decrease over the period. The fact that these trends are observed based on a rating that takes into account changes in weather and occupancy level, points to possibilities of other contributing factors. There are, for example, possibilities of rising fuel prices, implications of the economic downturn or continued austerity on public spending that could have affected the patterns of energy use in the public sector. 


\begin{tabular}{lcccccccc}
\hline \multirow{2}{*}{ Main Benchmark Category } & \multicolumn{7}{c}{ Year-on-Year $\%$ Change in Median Fossil-thermal Rating } \\
& 2010 & 2011 & 2012 & 2013 & 2014 & 2015 & 2016 & Overall \\
\hline General Office & - & $-7 \%$ & $-4 \%$ & $5 \%$ & $-4 \%$ & $-2 \%$ & $-4 \%$ & $-17 \%$ \\
Cultural Activities & - & $-1 \%$ & $-8 \%$ & $4 \%$ & $2 \%$ & $-10 \%$ & $11 \%$ & $-4 \%$ \\
Schools And Seasonal Public & - & $-2 \%$ & $-5 \%$ & $1 \%$ & $-1 \%$ & $-5 \%$ & $-1 \%$ & $-13 \%$ \\
Buildings & & & & & & & & \\
University Campus & - & $-4 \%$ & $-4 \%$ & $2 \%$ & $-4 \%$ & $-2 \%$ & $0 \%$ & $-11 \%$ \\
Clinic & - & $-5 \%$ & $-7 \%$ & $-8 \%$ & $11 \%$ & $-11 \%$ & $-8 \%$ & $-26 \%$ \\
Hospital - Clinical And Research & - & $-4 \%$ & $4 \%$ & $-1 \%$ & $-7 \%$ & $7 \%$ & $-11 \%$ & $-13 \%$ \\
Long Term Residential & - & $-8 \%$ & $4 \%$ & $-3 \%$ & $-6 \%$ & $-6 \%$ & $-3 \%$ & $-20 \%$ \\
General Accommodation & - & $-7 \%$ & $0 \%$ & $-4 \%$ & $-1 \%$ & $-8 \%$ & $-4 \%$ & $-22 \%$ \\
Emergency Services & - & $-2 \%$ & $-2 \%$ & $2 \%$ & $0 \%$ & $-5 \%$ & $-5 \%$ & $-12 \%$ \\
\hline
\end{tabular}

The trends' changes in electrical and fossil-thermal performances of public sector observed in this study suggest that many public-sector buildings have become considerably less intensive in energy consumption.

\section{Discussions}

\section{Developing a Deeper Understanding of Trends}

The study assessed data from the Display Energy Certificate scheme which is the largest dataset of its kind in the UK. Analysing the patterns of energy use of public sector buildings over a seven-year period helped develop a deeper understanding of the changes and highlighted the importance of long-term monitoring. The decreasing trend of electrical and fossil-thermal EUI of buildings in most categories suggested that positive changes took place in the public sector during this period, adding to the growing evidence from similar studies $(12,13,16)$. This suggests that the possibilities of increasing energy efficiency through changes to Building Regulations may have been effective to a certain extent in improving thermal performances of buildings. The gradually increasing intensity of electricity use in schools and hospitals on the other hand shows that these sectors may benefit from a focussed attention for improving their efficiency. These are changes which would not have been observed without analysing such a large dataset which emphasises the importance of continued monitoring and tracking at regular intervals for long periods.

Despite the benefits of such analysis, the study also highlights the lack of understanding of why such changes took place. Such high-level study is useful for understanding the directions of trends for which speculations can be made about potential factors behind the changes based on published statistics and findings from previous studies. Due to insufficient information on contextual factors however it is often difficult to understand the root causes behind these changes which would be extremely valuable for future planning. Developing a deeper understanding of the underlying causes, whether they are due to a targeted policy measure such as the DEC scheme or a consequence of broader changes such as economic down turn, is therefore needed. Such an understanding would support developing appropriate strategies for improving the energy efficiency of the non-domestic building stock and their contribution to the UK's 2050 target. 


\section{Improving How Energy Performance Data is Shared in the UK}

As demonstrated in the study, a key benefit of having the DEC scheme is that it enables monitoring and tracking of the energy performance of public buildings. Moreover, it is one of very few frameworks in the UK that stores building energy performance data at a large scale collected at regular intervals and that is public in nature. This means that the data can be shared with the public without concerns associated with data protection regulations or serving interests of specific organisations. This is particularly important in the UK as little action has taken place by public bodies to fully exploit the data for driving actions on energy efficiency (3). Public access to such data therefore means other entities such as universities can provide evidence to support various stakeholders make informed decisions on for example setting design targets for new buildings or targeting capital investments for improving energy efficiency of state-funded schools.

The release of such a large dataset by the Department for Communities and Local Government (DCLG) is certainly a positive step forward. There are however areas that could be improved. What was perhaps the most noticeable from the released data was that not all variables from the underlying database were included. Gaining access to all variables would have provided an opportunity to filter and disaggregate the data for developing a deeper understanding of the performance of public sector buildings $(13,16)$. Developing benchmarks that reflect the changes observed in this study would for example provide more relevant reference points. The frequency of data disclosure is another aspect that could be improved for the public benefit. Following the release of all DECs lodged until 2016, plans for further disclosure currently remains unclear. One of the strengths of the DECs scheme comes from its mandatory requirement for eligible buildings to report energy performance on an annual basis. Providing public access to the data at regular intervals would therefore provide a basis for tracking and understanding changes in patterns of energy use as and when they occur.

\section{Framework for Monitoring Long-term Changes in Energy Performance}

Analysing the long-term trend of energy use of public buildings highlights benefits of understanding how the patterns have changed over a seven-year period. The study also revealed considerable gaps in knowledge. Private sector, which includes retail and commercial office premises, accounts for significant proportion of the stock and yet there is limited knowledge about how the patterns of energy use of such buildings have changed and are likely to change in the future $(10,24,25)$. Keeping track of changes in performance of these buildings would therefore be essential for understanding the progress and making appropriate decisions towards the UK's 2050 emission reduction targets. To bridge this gap, developing a framework similar to the US Building Performance Database, that can act as a central point for collecting and analysing vast energy performance data from both private and public sectors, would be invaluable.

Developing such a framework in the UK requires understanding and identifying ways for overcoming current challenges. Utilising existing frameworks such as the DEC scheme is likely to be difficult for various reasons such as the lack of interest in exploiting the data by the government (3). An alternative option would be to consider a framework that resides outside the regulatory framework. Such an approach would allow continued development and adaptation to future changes in data landscape to take place whilst avoiding bureaucratic procedures. Another challenge is associated with collecting sufficient existing and new data from across the sector in the absence of the mandatory nature of the DEC scheme. One possibility would be to explore intelligent data gathering methods such as 
crowd-sourcing or gamification that incentivise data sharing from individuals (26). This would require developing a deeper understanding of how relevant stakeholders, such as energy officers that have access to relevant data, operate and their motivations for sharing data.

\section{Conclusions}

This study aimed to provide insights on the latest data for the energy performance of public sector non-domestic buildings in the UK as well as how the patterns of energy use have changed between 2010 and 2016.

The study found noticeable differences between the actual data and the benchmark values given in CIBSE TM46. This adds to the growing body of similar evidence for other building types and reinforces the need to use available data for providing various stakeholders with energy benchmarks that are more representative of the latest patterns. Observing decreases in electricity use in most categories and a general decrease in fossil-thermal energy use indicated positive changes were made over the past seven years. Some categories that showed an increasing trend in electricity use over the same period, on the other hand, raised concerns due to difficulties associated with regulating plug-loads in the UK. These findings highlighted the importance of monitoring trends and understanding causes behind changes to support developing effective strategies and policies. The study also discussed benefits and limitations of the current framework for collecting and sharing metered energy performance data from across the stock. Public release of such a large data such as DECs is unprecedented in the UK and is an accomplishment by the government which has encouraged open access to data for public benefit. Various limitations of the DEC scheme however mean that it would be more feasible to seek alternative means for gathering and sharing data from across non-domestic buildings.

To summarise, the study concludes there is a case for developing a flexible and sustainable framework that facilitates gathering and sharing energy data from both public and private sectors at regular intervals. Such a framework would provide various stakeholders with an improved understanding of the latest and long-term trends helping them make informed decisions for improving energy efficiency of the UK's non-domestic buildings.

\section{Acknowledgements}

This study was undertaken as part of a research project "Benchmarking and assessing energy consumption for the UK non-domestic stock" which is partially funded by CIBSE via UCL. The study was also partially supported by EPSRC funded RCUK Centre for Energy Epidemiology (CEE): the study of energy demand in a population (EP/K011839/1). 


\section{References}

1. Pérez-Lombard L, Ortiz J, Pout C. A review on buildings energy consumption information. Energy Build [Internet]. 2008 [cited 2011 Jul 26];40(3):394-8. Available from: http://linkinghub.elsevier.com/retrieve/pii/S0378778807001016

2. Hong SM, Paterson G, Burman E, Steadman P, Mumovic D. A comparative study of benchmarking approaches for non-domestic buildings: Part 1 - Top-down approach. Int J Sustain Built Environ. 2014 Apr;2(2):119-30.

3. Cohen $\mathrm{R}$, Bordass $\mathrm{B}$. Mandating transparency about building energy performance in use. Build Res Inf [Internet]. 2015;(April):1-19. Available from:

http://www.tandfonline.com/doi/abs/10.1080/09613218.2015.1017416

4. HM Government. Climate Change Act 2008 (c. 27). 2008.

5. Yalcintas M, Ozturk UA. An energy benchmarking model based on artificial neural network method utilizing US Commercial Buildings Energy Consumption Survey ( CBECS ) database. Int J Energy Res. 2007;31(April 2005):412-21.

6. Sharp T. Energy benchmarking in commercial office buildings. In: Proceedings of the ACEEE 1996 Summer Study on Energy Efficiency in Buildings. 1996. p. 321-29.

7. Sharp T. Benchmarking Energy Use in Schools. In: ACEEE 1998 Summer Study on Energy Efficiency in Buildings. Washington, DC: ACEEE; 1998. p. 305-16.

8. DoE. Frequently Asked Questions About the Building Performance Database | Department of Energy [Internet]. [cited 2017 Sep 27]. Available from: https://energy.gov/eere/buildings/frequently-asked-questions-about-buildingperformance-database\#timeseries

9. Pérez-Lombard L, Ortiz J, González R, Maestre IR. A review of benchmarking, rating and labelling concepts within the framework of building energy certification schemes. Energy Build [Internet]. 2009 Mar [cited 2012 Mar 15];41(3):272-8. Available from: http://linkinghub.elsevier.com/retrieve/pii/S037877880800220X

10. Armitage P, Godoy-Shimizu D, Steemers K, Chenvidyakarn T. Using Display Energy Certificates to quantify public sector office energy consumption. Build Res Inf [Internet]. 2014;43(6):691-709. Available from:

http://www.tandfonline.com/doi/full/10.1080/09613218.2014.975416\#.Vkm1J5kZwXc. mendeley

11. Brown N, Wright a. J, Shukla a., Stuart G. Longitudinal analysis of energy metering data from non-domestic buildings. Build Res Inf [Internet]. 2010 Feb [cited 2015 Jan 13];38(1):80-91. Available from:

http://www.tandfonline.com/doi/abs/10.1080/09613210903374788

12. Godoy-Shimizu D, Armitage P, Steemers K, Chenvidyakarn T. Using Display Energy Certificates to quantify schools energy consumption. Build Res Inf. 2011;39(6):37-41.

13. Hong SM, Paterson G, Mumovic D, Steadman P. Improved benchmarking comparability for energy consumption in schools. Build Res Inf. 2013;42(01):47-61.

14. Jones PG. A review of energy benchmarks in the Northern Ireland public estate. In: CIBSE-ASHRAE TECHNICAL SYMPOSIUM. Dublin, Ireland; 2014. p. 1-13.

15. Jones $\mathrm{P}$, Turner R, Browne D, Illingworth $\mathrm{P}$. Energy benchmarks for public sector buildings in Northern Ireland. In: Proceedings of CIBSE National Conference, Dublin. 2000. p. 1-8. 
16. Hong SM, Steadman P. An Analysis of Display Energy Certificates for Public Buildings 2008 to 2012 [Internet]. 2013. Available from:

https://www.bartlett.ucl.ac.uk/energy/news/display-energy-certificates

17. Department For Communities and Local Government. Energy Performance of Buildings Data England and Wales [Internet]. [cited 2017 May 10]. Available from: https://epc.opendatacommunities.org/docs/guidance

18. SAS Institute Inc. The BOXPLOT Procedure: Styles of Box Plots :: SAS/STAT(R) 9.22 User's Guide [Internet]. 2014. Available from:

http://support.sas.com/documentation/cdl/en/statug/63347/HTML/default/viewer.htm\# statug_boxplot_sect017.htm\#statug.boxplot.schematic

19. Carbon Trust. Hospitals-Healthy budgets through energy efficiency. London, UK; 2010.

20. DCLG. Improving the energy efficiency of our buildings. London, UK; 2015.

21. Carbon Trust. Hospitals - healthy budgets through energy efficiency. London; 2010.

22. ONS. Public sector employment, UK - Office for National Statistics [Internet]. [cited 2017 Jul 6]. Available from:

https://www.ons.gov.uk/employmentandlabourmarket/peopleinwork/publicsectorperso nnel/bulletins/publicsectoremployment/mar2017

23. Global Action Plan. UK Schools Carbon Footprint Scoping Study [Internet]. Stockholm Environment Institute; 2006 [cited 2013 Jul 31]. p. 1-76. Available from: http://www.sd-commission.org.uk/data/files/publications/GAP-Final-Report.pdf

24. Bruhns H. Property taxation data for nondomestic buildings in England and Wales. Environ Plan B Plan Des. 2000;27(1):33-49.

25. Carbon Trust. Building the future today - Transforming the economic and carbon performance of the buildings we work in (CTC765). United Kingdom: Carbon Trust; 2009.

26. Robertson C, Mumovic D, Hong SM. Crowd-sourced building intelligence: the potential to go beyond existing benchmarks for effective insight, feedback and targeting. Intell Build Int. 2015 Jan 7;(January 2015):1-14.

\section{List of Figures}

Figure 1 Changing distribution of building floor area by year

Figure 2 Description of parts of box plot generated by SAS (Source: SAS Institute Inc. 2014)

Figure 3 Box plot of electrical EUI of buildings by main benchmark category

Figure 4 Comparison of electrical operational rating between the latest DEC data and adjusted CIBSE TM46 benchmarks. 95\% confidence interval are displayed at the end of each bar.

Figure 5 Box plot of weather-corrected fossil-thermal EUI of buildings by main benchmark category. Note that outliers above and below upper and lower fences, respectively, are not displayed for clarity ...... 
Figure 6 Comparison of fossil-thermal rating between the latest DEC data and adjusted CIBSE TM46 benchmarks. 95\% confidence interval are displayed at the end of each bar. . 12

Figure 7 Distribution of floor area of buildings (or sites) in each benchmark category 13

Figure 8 Distribution of electrical EUI by floor area for each main benchmark category $(C 1=$ General Office, H4 = Cultural Activities, S3 = Schools And Seasonal Public Buildings, S4 = University Campus, S5 = Clinic, S6 = Hospital - Clinical And Research, S7 = Long Term Residential, S8 = General Accommodation, S9 = Emergency Services)

Figure 9 Distribution of weather-corrected EUI by floor area for each main benchmark category $(\mathrm{C} 1=$ General Office, $\mathrm{H} 4=$ Cultural Activities, $\mathrm{S} 3=$ Schools And Seasonal Public Buildings, S4 = University Campus, S5 = Clinic, S6 = Hospital - Clinical And Research, S7 = Long Term Residential, S8 = General Accommodation, S9 = Emergency Services)

Figure 10 Distribution of conditioning strategies in buildings by main benchmark category . 15

Figure 11 distribution of electrical EUI of buildings by building environment and category (H\&NV = Heating and Natural Ventilation, MM/NV = Mixed-mode with Natural Ventilation, $\mathrm{MM} / \mathrm{MV}=$ Mixed-mode with Mechanical Ventilation, H\&MV = Heating and Mechanical Ventilation, $\mathrm{AC}=$ Air Conditioning)

Figure 12 distribution of weather-corrected fossil-thermal EUI of buildings by building environment and category

Figure 13 Changes in patterns of electrical energy use of selected non-domestic buildings between 2010 and 2016 .

Figure 14 Changes in patterns of fossil-thermal energy use of selected non-domestic buildings between 2010 and 2016 . 